\title{
Influence of liquid structure on diffusive isotope separation in molten silicates and aqueous solutions
}

\author{
James M. Watkins ${ }^{\mathrm{a}, \Uparrow}$, Donald J. DePaolo ${ }^{\mathrm{a}, \mathrm{b}, 1}$, Frederick J. Ryerson ${ }^{\mathrm{c}, 2}$, \\ Brook T. Peterson ${ }^{a, 3}$ \\ apepartment of Earth and Planetary Science, University of California, Berkeley, CA 94720-4767, USA \\ barth Sciences Division, Lawrence Berkeley National Laboratory, Berkeley, CA 94720-4767, USA \\ CLawrence Livermore National Laboratory, L-638, LLNL, Livermore, CA 94550, USA
}

\begin{abstract}
Molecular diffusion in natural volcanic liquids discriminates between isotopes of major ions (e.g., Fe, $\mathrm{Mg}$, Ca, and $\mathrm{Li}$ ). Although isotope separation by diffusion is expected on theoretical grounds, the dependence on mass is highly variable for different elements and in different media. Silicate liquid diffusion experiments using simple liquid compositions were carried out to further probe the compositional dependence of diffusive isotopic discrimination and its relationship to liquid structure. Two diffusion couples consisting of the mineral constituents anorthite ( $\mathrm{CaAl}_{2} \mathrm{Si}_{2} \mathrm{O} 8$; denoted AN), albite ( $\mathrm{NaAlSi} 3 \mathrm{O} 8$; denoted $\mathrm{AB}$ ), and diopside (CaMgSi2O6; denoted $\mathrm{DI}$ ) were held at $1450^{\circ} \mathrm{C}$ for $2 \mathrm{~h}$ and then quenched to ambient pressure and temperature. Major-element as well as $\mathrm{Ca}$ and $\mathrm{Mg}$ isotope profiles were measured on the recovered quenched glasses. In both experiments, Ca diffuses rapidly with respect to Si. In the AB-AN experiment, DCa/DSi $~ 20$ and the efficiency of isotope separation for $\mathrm{Ca}$ is much greater than in natural liquid experiments where $\mathrm{DCa} / \mathrm{DSi} \sim 1$. In the $\mathrm{AB}-\mathrm{DI}$ experiment, $\mathrm{DCa} / \mathrm{DSi} \sim 6$ and the efficiency of isotope separation is between that of the natural liquid experiments and the $\mathrm{AB}-\mathrm{AN}$ experiment. In the $\mathrm{AB}-\mathrm{DI}$ experiment, $\mathrm{DMg} / \mathrm{DSi} \sim 1$ and the efficiency of isotope separation for $\mathrm{Mg}$ is smaller than it is for $\mathrm{Ca}$ yet similar to that observed for $\mathrm{Mg}$ in natural liquids.

The results from the experiments reported here, in combination with results from natural volcanic liquids, show clearly that the efficiency of diffusive separation of Ca isotopes is systematically related to the solvent-normalized diffusivity-the ratio of the diffusivity of the cation (DCa) to the diffusivity of silicon (DSi). The results on Ca isotopes are consistent with available data on $\mathrm{Fe}, \mathrm{Li}$, and $\mathrm{Mg}$ isotopes in silicate liquids, when considered in terms of the parameter $\mathrm{D}_{\text {cation }} / \mathrm{DS}_{\text {Si }}$. Cations diffusing in aqueous solutions display a similar relationship between isotopic separation efficiency and $\mathrm{D}_{\text {cation }}=\mathrm{DH}_{2} \mathrm{O}$, although the efficiencies are smaller than in silicate liquids. Our empirical relationship provides a tool for predicting the magnitude of diffusive isotopic effects in many geologic environments and a basis for a more comprehensive theory of isotope separation in liquid solutions. We present a conceptual model for the relationship between diffusivity and liquid structure that is consistent with available data.
\end{abstract}

\footnotetext{
« Corresponding author. Tel.: +1 510642 0977; fax: +1 510642 9520.

E-mail addresses: jwatkins@berkeley.edu (J.M. Watkins), depaolo@eps.berkeley.edu (D.J. DePaolo), ryerson1@llnl.gov (F.J. Ryerson), bpeterson@berkeley.edu (B.T. Peterson).

${ }^{1}$ Tel.: +1 510643 5063; fax: +1 5106429520 .

${ }^{2}$ Tel.: +1 925422 6170; fax: +1 9254223118 .

${ }^{3}$ Tel.: +1 510642 0977; fax: +1 5106429520 .
}

\section{INTRODUCTION}

Natural variations in the isotopic composition of some 50 chemical elements are used in geochemistry for studying transport processes, estimating temperature, and even for classifying planets and meteorites (Johnson et al., 2004). Within the past decade there has been growing interest in 
measuring isotopic variations in a wider variety of elements, and improved techniques make it possible to measure very small effects (Eiler and Shauble, 2004; Ono et al., 2006; Eiler, 2007). Interpreting the small isotopic variations has required a closer look at how transport processes affect isotopic distributions (Eiler and Shauble, 2004). It is now recognized that the mass dependence of isotopic transport coefficients can be variable both in absolute value and in functional form for different elements and molecules (Weingartner et al., 1989; Young et al., 2002).

For many years the thinking among geochemists on isotope fractionation (or separation) by diffusion has been guided by application of the laws of kinetic theory - wherein diffusion is the result of purely translational motion and elastic collisions of geometrically simple molecules. Even in some dilute gas systems, however, there are deviations from the expected behavior (e.g., Merlivat, 1978; Barkan and Luz, 2007; Luz et al., 2009). The picture becomes significantly more complicated in liquids because chemical bonding, and the shape and rotation of molecules, influence transport. There are models that adequately describe diffusive isotope separation in some simple liquids, but for more complex liquid solutions such as silicate melts, where the compositions of the diffusing species are ambiguous and dynamic, there is no general theory (see Appendix A.1). In a previous study (Watkins et al., 2009) involving natural magmatic liquids, we observed isotopic fractionations that suggested a composition-dependence to the diffusive isotope separation for calcium. In those experiments the compositional dependence was equivocal because of other possible contributing effects and the fact that natural silicate melt compositions are complicated.

In this diffusion study we use silicate liquids of simple composition to further probe the compositional depen-

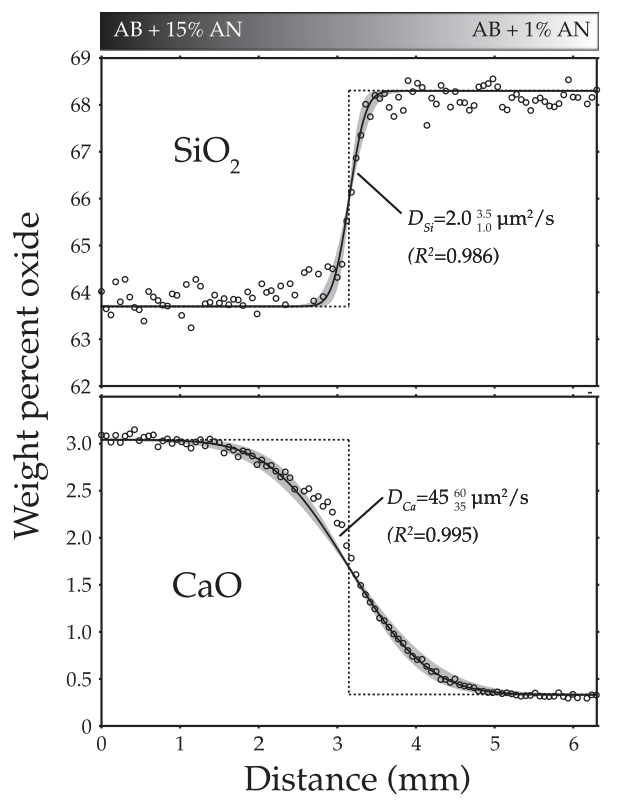

dence of diffusive isotopic discrimination and its relationship to liquid structure. All of the starting materials are combinations of the three mineral constituents anorthite $\left(\mathrm{CaAl}_{2} \mathrm{Si}_{2} \mathrm{O}_{8}\right.$; denoted $\left.\mathrm{AN}\right)$, albite $\left(\mathrm{NaAlSi}_{3} \mathrm{O}_{8}\right.$; denoted $\mathrm{AB})$, and diopside $\left(\mathrm{CaMgSi}_{2} \mathrm{O}_{6}\right.$; denoted $\left.\mathrm{DI}\right)$, so that the resulting silicate liquids are considerably less complicated than natural basalt and rhyolite. Two diffusion couples were constructed: one consisting of $\mathrm{AB}$ and $\mathrm{AN}(1 \% \mathrm{AN}$ versus $15 \% \mathrm{AN})$, and the other consisting of $\mathrm{AB}$ and $\mathrm{DI}$ $(1 \%$ DI versus $15 \% \mathrm{DI})$. The ends of the diffusion couple with a greater proportions of $\mathrm{AN}$ (or DI) have much higher $\mathrm{Ca}$ concentration than the AB-rich ends, and hence Ca diffuses down a substantial concentration gradient during the experiments. Albite was chosen as the main component of the liquids because of its relatively low melting temperature (1203 ${ }^{\circ} \mathrm{C}$ at $8 \mathrm{kbar}$; Birch and LeComte, 1960), permitting us to use temperature and pressure conditions similar to those used in previous experiments on natural magmatic compositions (Richter et al., 2003, 2008, 2009; Watkins et al., 2009). The variation in $\mathrm{SiO}_{2}$ concentration among the synthetic starting compositions is also relatively small (Figs. 1 and 2). As diffusion coefficients for most elements in silicate liquids vary with the concentration of $\mathrm{SiO}_{2}$, this characteristic simplifies analysis as we can assume that the diffusion coefficients are uniform across the couple, and that they do not change over the course of the experiment.

\section{EXPERIMENTAL METHODS}

\subsection{Starting materials}

Synthetic mineral compositions were made by weighing out dehydrated, reagent-grade oxides and carbonates and mixing them together in ethanol as a slurry in an

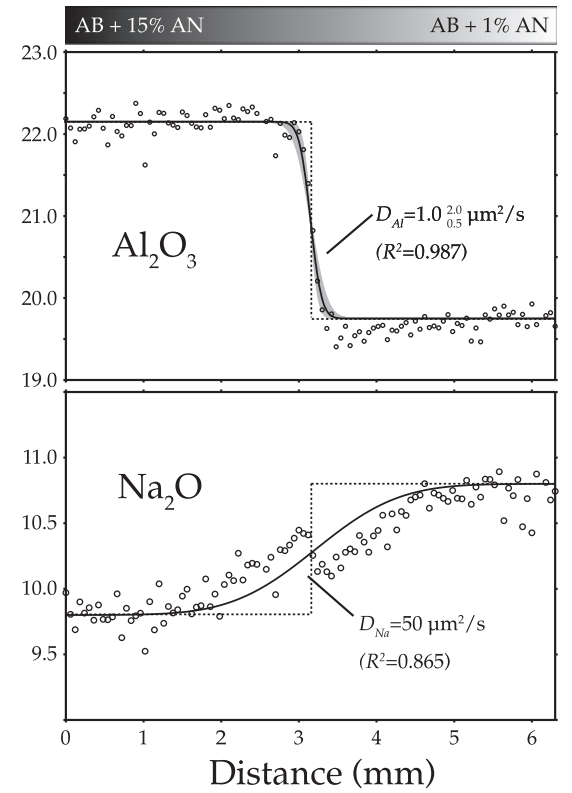

Fig. 1. Chemical concentration profiles of major cations from diffusion experiments involving simplified molten silicate composition (ABAN) as measured by electron microprobe. Dashed lines represent the starting concentrations and initial condition for the diffusion model. Solid lines are best-fit model profiles with associated diffusivities $\left(D_{i}\right)$. The diffusivity $D_{i}$ of each of the major cations is roughly constant across the diffusion couple, as evidenced by the observed symmetry in each of the profiles about the initial interface between starting liquids. An estimate of the uncertainty in $D_{i}$ is obtained from the range of model profiles spanned by the shaded area. 
collectors. For considerations regarding beam intensities and corrections for machine mass discrimination, the reader is referred to DePaolo (2004) and Watkins (2010). The $\mathrm{Ca}$ isotope composition is expressed as (DePaolo, 2004)

$\delta^{(44 / 40)} \mathrm{Ca}=1000 \times\left[\frac{\left({ }^{44} \mathrm{Ca} /{ }^{40} \mathrm{Ca}\right)_{\text {sample }}}{0.0212076}-1\right]$,

and all $\mathrm{Ca}$ isotope data are reported in Table 2.

$\mathrm{Mg}$ isotope measurements were carried out at Lawrence Berkeley National Lab on a Micromass Isoprobe multi-collector inductively coupled plasma mass spectrometer (MCICP-MS) using a sample-standard bracketing technique (Galy et al., 2003). Sample concentrations between 500 and $1000 \mathrm{ppb} \mathrm{Mg}$ in dilute $\mathrm{HNO}_{3}$ (matched to bracketing standard concentrations) were introduced through a CETAC Aridus desolvating nebulizer using only $\mathrm{Ar}$ gas to avoid $\mathrm{CN}$-interference. The Isoprobe uses a gas collision cell to normalize ion beam kinetic energy and remove isobaric interferences. Based on experiments, gas bleed rates into the cell were found to be optimal at $8.0 \mathrm{~mL} / \mathrm{min}$ for $\mathrm{He}$ and $0.8 \mathrm{~mL} / \mathrm{min}$ for $\mathrm{H}$. Cone extraction potential was set at $190 \mathrm{~V}$, and the remaining tuning parameters were optimized daily for maximum signal intensity. Total beam varied from 6 to $9 \mathrm{~V}$. The $\mathrm{Mg}$ isotope composition is expressed as:

$\delta^{(26 / 24)} \mathrm{Mg}=1000 \times\left[\frac{\left({ }^{26} \mathrm{Mg} /{ }^{24} \mathrm{Mg}\right)_{\text {sample }}}{\left({ }^{26} \mathrm{Mg} /{ }^{24} \mathrm{Mg}\right)_{\text {DSM3 }}}-1\right]$.

All Mg isotope measurements are normalized to the DSM3 standard (Young and Galy, 2004) and are reported in Table 2.

Each reported data point consists of the average of 2-7 replicate measurements (except ABDI4-7); each replicate consists of a single $60 \mathrm{~s}$ on-peak background measurement and a block of $2010 \mathrm{~s}$ static measurements, bracketed by similar measurements of the DSM3 mono-elemental standard. The system was washed for 5-10 min with successive dilute $\mathrm{HNO}_{3}$ solutions between measurement cycles. Replicates of the Cambridge1 mono-elemental standard $(n=9)$ yield $\delta^{(26 / 24)} \mathrm{Mg}=-2.73 \pm 0.35$, within uncertainty of the established value of $-2.58 \pm 0.14$ (Galy et al., 2003).

\section{RESULTS}

\subsection{Major element diffusion profiles}

Figs. 1 and 2 show the major-element diffusion profiles corresponding to the $\mathrm{AB}-\mathrm{AN}$ and $\mathrm{AB}-\mathrm{DI}$ experiments, respectively. In both experiments, $\mathrm{Ca}$ and $\mathrm{Na}$ are observed to diffuse more rapidly than the network-forming cations $\mathrm{Si}$ and Al. This difference is different from what is observed in natural silicate liquids under similar experimental conditions, where the length scales of $\mathrm{Ca}, \mathrm{Na}$, and $\mathrm{Si}$ diffusion are nearly identical (Richter et al., 2003, 2008, 2009; Watkins et al., 2009). In the AB-DI experiment, $\mathrm{Mg}$ diffuses more slowly than $\mathrm{Ca}$ and $\mathrm{Na}$, its behavior resembling that of the network-forming cations. The slow diffusion of $\mathrm{Mg}$ relative to $\mathrm{Ca}$ has also been observed for tracer diffusion in liquids of nearly pure albite composition over the temperature range $645-1025^{\circ} \mathrm{C}$ (Rosalieb and Jambon, 2002).

\subsection{Ca and $\mathrm{Mg}$ isotope profiles}

Fig. 3 shows the $\mathrm{Ca}$ and $\mathrm{Mg}$ isotopic composition along the diffusion profiles. As the isotopic composition is initially uniform across the two diffusion couples $\left(\delta^{44} \mathrm{Ca}=-0.3 \%\right.$ o and $\delta^{26} \mathrm{Mg}=-1.2 \%$ ), the observed isotopic variability develops as a result of diffusion during the experiment. In the $\mathrm{AB}-\mathrm{AN}$ experiment (Fig. 3a), the variation in $\delta^{44} \mathrm{Ca}$ of $\sim 10 \%$ is the largest fractionation of $\mathrm{Ca}$ isotopes so far observed in such chemical diffusion experiments. In this experiment, the isotopic composition at the boundaries changed slightly from the initial condition, indicating that diffusive effects have reached both ends of the capsule. In the AB-DI experiment (Fig. 3b), the range in $\delta^{44} \mathrm{Ca}$ is $\sim 6 \%$, comparable to the maximum range previously observed in natural compositions, and the isotopic composition at both ends of the capsule is unchanged from the initial condition. In the same experiment, the range in $\delta^{26} \mathrm{Mg}$ is only $\sim 1.3 \%$ and the length scale of $\mathrm{Mg}$ isotope variability from the initial state is comparable to that for $\mathrm{Ca}$ isotopes. In both experiments, the overall shape of the profiles match those expected for the simplest model of chemical diffusion in which $\mathrm{Ca}$ and $\mathrm{Mg}$ diffuse in response to their own concentration gradients.

\section{ANALYSIS}

The essential and unexpected result of the experiments described above is that the $\mathrm{Ca}$ isotopic separation due to diffusion in chemically simple diffusion couples is both larger than observed in natural volcanic liquids (e.g., Richter et al., 2003; Watkins et al., 2009) and variable. It was originally postulated by Richter et al. (2003) based on the data available, that the $\mathrm{Ca}$ isotopic selectivity due to diffusion in

Table 1

Targeted versus measured bulk compositions of starting materials used in diffusion couple experiments. The difference between the target and measured compositions is not significant for the purpose of this study.

\begin{tabular}{llllllll}
\hline & & $\mathrm{CaO}$ & $\mathrm{MgO}$ & $\mathrm{SiO}_{2}$ & $\mathrm{Al}_{2} \mathrm{O}_{3}$ & $\mathrm{Na}_{2} \mathrm{O}$ & $\mathrm{Total}$ \\
\hline $85 \mathrm{AB}+15 \mathrm{AN}$ & Calculated & 3.02 & 0.00 & 64.91 & 22.02 & 10.05 & 100.00 \\
& Measured & 3.04 & - & 63.70 & 22.15 & 9.80 & 98.69 \\
$99 \mathrm{AB}+01 \mathrm{AN}$ & Calculated & 0.20 & 0.00 & 68.48 & 19.61 & 11.70 & 100.00 \\
& Measured & 0.33 & - & 68.30 & 19.75 & 10.80 & 99.18 \\
$85 \mathrm{AB}+15 \mathrm{DI}$ & Calculated & 3.88 & 2.79 & 66.75 & 16.53 & 10.05 & 100.00 \\
& Measured & 3.75 & 2.60 & 66.00 & 16.80 & 9.65 & 98.80 \\
$99 \mathrm{AB}+01 \mathrm{DI}$ & Calculated & 0.26 & 0.19 & 68.61 & 19.25 & 11.70 & 100.00 \\
& Measured & 0.37 & 0.30 & 67.70 & 19.30 & 10.90 & 98.57 \\
\hline
\end{tabular}


Table 2

$\mathrm{Ca}$ and $\mathrm{Mg}$ isotope compositions measured on post-run diffusion couples. The isotopic compositions represent an average for each wafer; therefore the distance values are shifted slightly from the center of each wafer to account for the gradient in concentration across each wafer.

\begin{tabular}{|c|c|c|c|c|c|}
\hline \multicolumn{2}{|l|}{ Sample (wafer no.) } & Distance $(\mathrm{mm})$ & \multicolumn{2}{|c|}{$\delta^{44} \mathrm{Ca}^{\mathrm{a}}(\%)$} & No. of analyses \\
\hline \multicolumn{6}{|c|}{ Albite-anorthite experiment } \\
\hline ABAN2-1 & \multicolumn{2}{|r|}{6.019} & \multicolumn{2}{|c|}{-0.98} & 3 \\
\hline ABAN2-2 & \multicolumn{2}{|r|}{5.337} & \multicolumn{2}{|c|}{-3.19} & 2 \\
\hline ABAN2-3 & \multicolumn{2}{|r|}{4.724} & \multicolumn{2}{|c|}{-7.49} & 3 \\
\hline ABAN2-4 & \multicolumn{2}{|r|}{4.054} & \multicolumn{2}{|c|}{-7.86} & 2 \\
\hline ABAN2-5 & \multicolumn{2}{|r|}{3.431} & \multicolumn{2}{|c|}{-2.03} & 3 \\
\hline ABAN2-6 & \multicolumn{2}{|r|}{2.812} & \multicolumn{2}{|c|}{0.95} & 3 \\
\hline ABAN2-7 & \multicolumn{2}{|r|}{2.215} & \multicolumn{2}{|l|}{1.21} & 2 \\
\hline ABAN2-8 & \multicolumn{2}{|r|}{1.558} & \multicolumn{2}{|l|}{0.50} & 2 \\
\hline ABAN2-9 & \multicolumn{2}{|r|}{0.960} & \multicolumn{2}{|l|}{0.03} & 2 \\
\hline ABAN2-10 & \multicolumn{2}{|r|}{0.300} & \multicolumn{2}{|l|}{0.07} & 2 \\
\hline Sample (wafer no.) & Distance $(\mathrm{mm})$ & $\delta^{44} \mathrm{Ca}^{\mathrm{a}}(\%)$ & No. of analyses & $\delta^{26} \mathrm{Mg}(2 \sigma)(\%)$ & No. of analyses \\
\hline \multicolumn{6}{|c|}{ Albite-diopside experiment } \\
\hline ABDI4-1 & 5.279 & -0.42 & 2 & $-1.40(29)$ & 3 \\
\hline ABDI4-2 & 4.678 & -1.43 & 3 & $-1.04(34)$ & 3 \\
\hline ABDI4-3 & 4.008 & -4.82 & 2 & $-1.51(47)$ & 7 \\
\hline ABDI4-4 & 3.394 & -4.86 & 2 & $-2.51(16)$ & 2 \\
\hline ABDI4-5 & 2.726 & -0.57 & 3 & $-1.45(17)$ & 3 \\
\hline ABDI4-6 & 2.148 & 0.68 & 2 & $-1.10(47)$ & 2 \\
\hline ABDI4-7 & 1.557 & 0.31 & 2 & $-1.15(-)$ & 1 \\
\hline ABDI4-8 & 0.900 & -0.27 & 2 & $-1.12(87)$ & 3 \\
\hline ABDI4-9 & 0.300 & -0.33 & 2 & $-1.23(42)$ & 3 \\
\hline
\end{tabular}

${ }^{\text {a }}$ Uncertainties in $\delta^{44} \mathrm{Ca}$ are within $\pm 0.15 \%$.
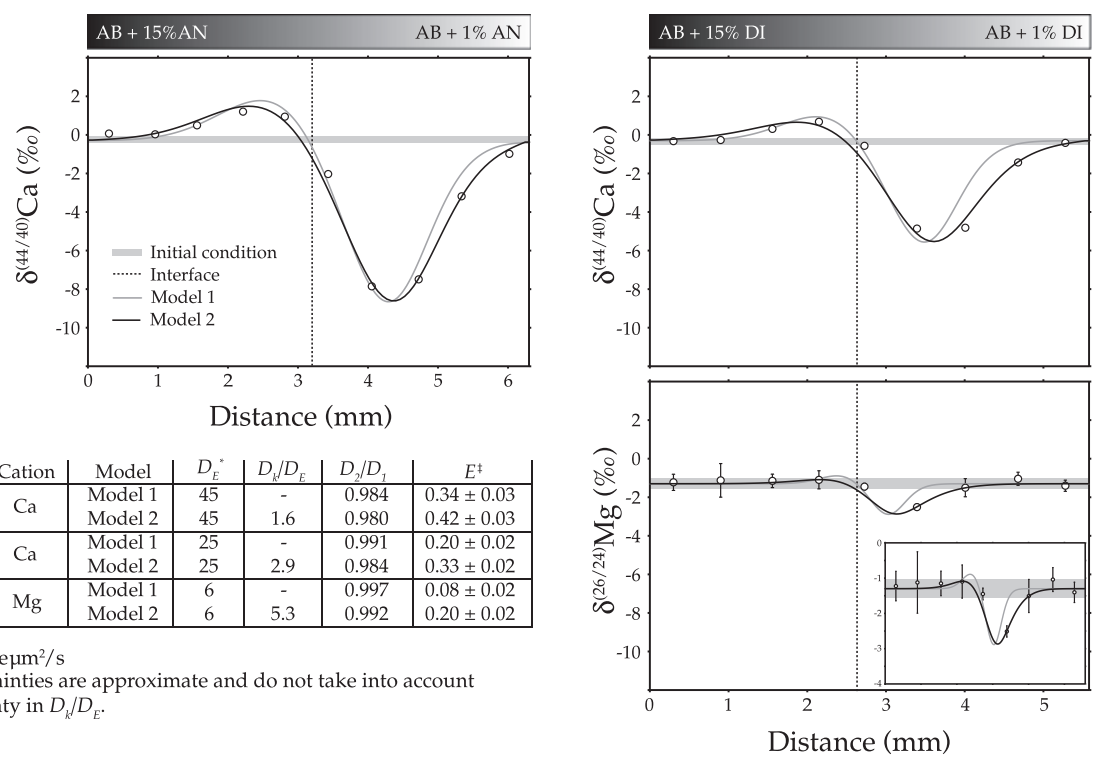

Fig. 3. $\mathrm{Ca}$ and $\mathrm{Mg}$ isotope profiles from the $\mathrm{AB}-\mathrm{AN}$ and $\mathrm{AB}-\mathrm{DI}$ diffusion experiments depicted in Figs. 1 and 2, showing isotopic separation by diffusion. The initial isotopic ratio was constant across the experimental charge and is denoted by the gray horizontal bar. Solid lines are model isotope profiles (see text) used to quantify the efficiency of isotope separation $E$, which is equal to $2 \ln \left(D_{2} / D_{1}\right) / \ln \left(m_{1} / m_{2}\right)$, where $m$ is the solute element's atomic mass and subscripts denote different isotopes.

silicate liquids might be roughly constant; that is, independent of liquid composition. Watkins et al. (2009) provided evidence that the isotopic selectivity might be more pronounced in high silica liquids, but the complexity of the experimental results did not allow for more definitive con- clusions. The present results, however, show unequivocally that $\mathrm{Ca}$ isotope fractionation during diffusion can be highly variable. In the following section we analyze this variability and show that the efficiency of isotope separation appears to be correlated with both the magnitude of the diffusivity, 
and more precisely, the ratio of the Ca diffusivity to that of $\mathrm{Si}$. The systematic relationships we have discovered allow us to move closer to a general model of isotopic fractionation during diffusion in silicate liquids, and also shed light on the bonding of cations within these liquids and the structure of the liquids themselves.

\subsection{Model for the elemental diffusion profiles}

In non-equilibrium thermodynamics, fluxes are directly proportional to forces. For chemical fluxes, the forces are gradients in chemical potential, but since chemical potentials are difficult to measure, gradients in concentration are generally used as an approximation. In the most general model of chemical diffusion, the flux of component $i$ may be driven by a concentration gradient in any of the other components $j$ :

$J_{i}=-\sum_{j=1}^{n-1} D_{i j} \nabla C_{j}$,

where the $D_{i j}$ 's are terms in the multicomponent diffusivity matrix and $C_{j}$ is the concentration of component $j$. Eq. (1) does not specifically account for the fact that chemical elements have isotopes, but it has been demonstrated by experiment that isotopic species diffuse at different rates depending on mass. To model these effects, it has been customary to treat each isotope as an independent chemical species, diffusing in response to its own concentration gradient. This ignores the role of isotopic exchange, or self diffusion, superimposed on chemical diffusion. It is therefore preferable to write the diffusive flux of isotope $k$ of element $i$ as (Liang, 1994; Richter et al., 1999; Liang, 2010):

$J_{i}^{k}=-D_{i}^{k} \nabla C_{i}^{k}-\sum_{j=1}^{n-1} f_{i}^{k}\left(D_{i j}-\delta_{i j} D_{i}^{k}\right) \nabla C_{j}$,

where $D_{i}^{k}$ is the self diffusion coefficient; $C_{i}^{k}$ is the concentration of isotope $k ; f_{i}^{k}$ is the mole fraction of isotope $k$ in element $i$, and $\delta_{i j}=1$ if $i=j$ and $\delta_{i j}=0$ if $i \neq j$. When the elements of the diffusivity matrix are unknown, as is the case in our systems, Eq. (2) can be cast in terms of the effective binary diffusion coefficient (EBDC) (Liang, 2010):

$J_{i}^{k}=-D_{i}^{k} \nabla C_{i}^{k}-f_{i}^{k}\left(D_{i}^{E}-D_{i}^{k}\right) \nabla C_{i}$,

where $D_{i}^{E}$ is the EBDC. The EBD model obscures aspects of diffusion that may be of interest, and is only applicable when the chemical diffusion profile is monotonic. In our previous experiments on natural volcanic liquids (Watkins et al., 2009) we observed that isotopic discrimination for $\mathrm{Ca}$ isotopes during diffusion depends on the magnitude and direction of the $\mathrm{Al}$ concentration gradient relative to those of the $\mathrm{Ca}$ concentration gradient. To model these effects we used a multi-component diffusivity matrix that explicitly accounts for $\mathrm{Ca}-\mathrm{Al}$ coupling. In this study, however, the mass dependence on the off-diagonal terms cannot be resolved because the $\mathrm{Al}, \mathrm{Si}$, and $\mathrm{Na}$ gradients are relatively small (see Appendix A.2). The advantage of the EBD model is that only one parameter $\left(D_{i}^{E}\right)$ is required to obtain a chemical diffusion profile and nearly all diffusivi- ties in minerals and melts are obtained using this approach (Zhang, 2010).

To simplify the notation we remove the subscripts $i$ except where necessary in later sections to distinguish between EBDCs of different elements. Substituting $C_{k}=f_{k} C$ and applying mass conservation leads to the following onedimensional diffusion equation (assuming the $D$ 's are constant):

$\frac{\partial C_{k}}{\partial t}=D_{E} f_{k} \nabla^{2} C+\left(D_{E}+D_{k}\right) \nabla C \nabla f_{k}+D_{k} C \nabla^{2} f_{k}$.

In this formulation, there are actually two potentials driving the net flux of an isotope: $\nabla C$ represents a driving force for chemical homogenization and $\nabla f_{k}$ represents a driving force for isotopic homogenization. Eq. (4) holds for two end-member scenarios. When there is only one isotope $\left(f_{k}=1\right)$ we recover the effective binary diffusion equation:

$\frac{\partial C}{\partial t}=D_{E} \nabla^{2} C$.

When the elemental composition is uniform ( $C=$ constant $)$ but there are gradients in isotopic ratios, we recover the self diffusion equation:

$\frac{\partial f_{k}}{\partial t}=D_{k} \nabla^{2} f_{k}$

which describes diffusion of an isotope ratio.

Numerical solutions to the one-dimensional form of Eq. (4) were calculated using a explicit finite difference scheme in MATLAB. For our experiments the appropriate boundary conditions are zero flux $\left(\partial C_{k} / \partial x=0\right)$ at either end of the capsule. The code was validated against the analytical solution to Eq. (5) with zero-flux boundary conditions given by Trial and Spera (1994).

\subsection{Comparison between model and measured elemental profiles}

Model versus measured diffusion profiles for $\mathrm{Ca}, \mathrm{Mg}$, $\mathrm{Na}, \mathrm{Al}$ and $\mathrm{Si}$ and the associated EBDCs for both diffusion couples are shown in Figs. 1 and 2. Note that the elemental profiles for $\mathrm{Ca}$ and $\mathrm{Mg}$ are insensitive to the self diffusivities because $\nabla C \gg \nabla f_{k}$. The contrast between $\mathrm{Ca}$ and Si diffusivity is largest in the $\mathrm{AB}-\mathrm{AN}$ experiment where the diffusivity of $\mathrm{Ca}$ is greater than that of $\mathrm{Si}$ by a factor of 22.5 $\left(D_{C a}=45 \mu \mathrm{m}^{2} / \mathrm{s}\right.$ and $\left.D_{S i}=2.0 \mu \mathrm{m}^{2} / \mathrm{s}\right)$. In the AB-DI experiment, where there is greater abundance of networkmodifying cations $(\mathrm{Mg}+\mathrm{Ca})$, the diffusivity of $\mathrm{Ca}$ is reduced $\left(D_{C a}=25 \mu \mathrm{m}^{2} / \mathrm{s}\right)$ and the diffusivity of Si is increased $\left(D_{S i}=4.0 \mu \mathrm{m}^{2} / \mathrm{s}\right)$ such that $D_{C a} / D_{S i}$ is about 6 . This latter value is still large in comparison to $D_{C a} / D_{S i}$ in natural silicate liquids, which is close to unity. In the same experiment, the diffusivity of $\mathrm{Mg}$ is less than that of $\mathrm{Ca}$ yet similar to that of $\mathrm{Si}$.

\subsection{Model for the isotope ratio profiles}

The $\mathrm{Ca}$ and $\mathrm{Mg}$ isotope ratio profiles require that the diffusion coefficients for the isotopes of $\mathrm{Ca}$ and $\mathrm{Mg}$ vary with mass. Assuming the ratio of isotopic diffusion coeffi- 
cients is constant, a single parameter $E$ describes the efficiency of isotope separation (after Schoen, 1958):

$E=2 \frac{\ln \left(D_{2} / D_{1}\right)}{\ln \left(m_{1} / m_{2}\right)}$,

where $m_{k}$ is the mass of isotope $k$ and the $D$ 's are isotopespecific EBDCs. There is a mass dependence on $D_{k}$ (Richter et al., 1999) but it cannot be resolved using the setup of the $\mathrm{AB}-\mathrm{AN}$ and $\mathrm{AB}-\mathrm{DI}$ experiments wherein $\nabla C \gg \nabla f_{k}$. The parameter $E$ is related to the analogous parameter $\beta$ used by Richter et al. (2003), by the simple relationship $E=2 \beta$. The magnitude of $E$ is affected by the number and masses of other atoms whose motions are correlated with the motion of the atom of interest. Larger values of $E$ correspond to greater mass discrimination between isotopes and imply that the diffusing atom is decoupled from the motion of other atoms (Rothman and Peterson, 1965). The value of $E$ approaches unity for diffusion in gases but is generally much smaller in liquids and solids. Values for $D_{2} / D_{1}$ (i.e., $D^{44} \mathrm{Ca} / D^{40} \mathrm{Ca}$ ) can be obtained from the model fit to the isotopic profiles and $E$ derived from Eq. (7) and the isotopic masses of Ca.

\subsection{Comparison between model and measured isotope profiles}

Two sets of model profiles are compared to the measured isotope profiles in Fig. 3. The gray curves show the result when isotopic exchange superimposed on chemical diffusion is ignored; they represent the analytical solution to Eq. (5) (Trial and Spera, 1994) and involve the minimum number of free parameters required to generate a model isotope profile $\left(D_{E}\right.$ and $E$ ). In all three plots, the gray curves are in relatively good agreement with the $\mathrm{Ca}$ and $\mathrm{Mg}$ isotopic data. In detail, however, there is misfit in the low$(\mathrm{Ca}, \mathrm{Mg}$ ) side of the couple; the low- $\delta$ trough does not extend far enough into the low-concentration liquid.

The black curves show that a nearly perfect fit can be achieved once self diffusion is taken into account. The isotopic effects extend further into the low-concentration liquid because isotopic exchange affects $\delta$-values without contributing to the net elemental flux. The quality of the fits indicate that $D_{k}$ is greater than $D_{E}$ by a factor of about 2 for $\mathrm{Ca}$ and about 5 for $\mathrm{Mg}$ in albitic liquid at $1450{ }^{\circ} \mathrm{C}$, which is consistent with the observation that isotope ratios tend to reequilibrate faster than elemental concentrations by diffusion in molten silicates (Baker, 1989; Lesher, 1990, 1994; Van der Laan et al., 1994; Liang, 2010). It is important to emphasize that consideration of isotopic exchange superimposed on chemical diffusion increases the derived values of $E$, and that the correction to $E$ tends to increase with increasing $D_{k} / D_{E}$.

There is also significance in the nearly exact fit of the $\delta^{(44 / 40)} \mathrm{Ca}$ data on the high-Ca side of both experiments, because in most of the experiments conducted using natural basalt-rhyolite diffusion couples, linear variations in $\delta^{(44 /}$ ${ }^{40)} \mathrm{Ca}$ have been observed in the high- $\mathrm{Ca}$ end that could not be accounted for with a simplified chemical diffusion model (Richter et al., 2003). Such variations have been attributed to undesired temperature gradients in the experimental capsules because temperature gradients can pro- duce a similar isotopic signature (Richter et al., 2008). However, our failure to observe linear variations in $\delta^{(44 /}$ ${ }^{40)} \mathrm{Ca}$ in the $\mathrm{AB}-\mathrm{AN}$ and $\mathrm{AB}-\mathrm{DI}$ experiments, and in an isochemical experiment under the same conditions (Watkins et al., 2009), suggests that these unexpected isotopic effects in the natural systems have other causes. We postulate that non-ideal mixing may generate the unexpected isotopic gradients, reflecting a complex relationship between diffusive flux and concentration gradients near the interface of the diffusion couple. It may be noteworthy that mixing in the system albite-anorthite and albite-diopside is nearly athermal in the area of composition space spanned by our experiments (Navrotsky et al., 1989).

\section{DISCUSSION}

\subsection{Isotope separation by diffusion in silicate melts}

Our results demonstrate, in contrast to previous proposals (Richter et al., 2003; Watson and Müller, 2009) that diffusive isotopic separation for $\mathrm{Ca}$ is sensitive to even slight changes in liquid composition. The compositions of the diffusion couples are similar in terms of $\mathrm{SiO}_{2}$ content, and yet $E$ for $\mathrm{Ca}$ varies from 0.33 in the AB-DI experiment to 0.42 in the $\mathrm{AB}-\mathrm{AN}$ experiment. Both values are significantly greater than that found in natural silicate liquid experiments $(E=0.07-0.15)$, and show that there is no single value of $E$ that can describe the diffusive fractionation behavior of $\mathrm{Ca}$ isotopes in silicate liquids. $E_{C a}$ does, however, appear to be strongly correlated with the ratio $D_{C a}$ $D_{S i}$ (Fig. 4), which represents the ratio of the diffusivity of a "solute" component relative to that of the "solvent" component, in this case represented by Si. Among the silicate melt compositions for which diffusive fractionation of calcium has been measured, $D_{C a} / D_{S i}$ varies by a factor of $\sim 200$ and $E$ varies systematically between 0.07 and 0.42 . The variation in $D_{i} / D_{S i}$ is even larger, $\sim 1000$, if experimental data for $\mathrm{Ca}, \mathrm{Mg}, \mathrm{Fe}$ and $\mathrm{Li}$ are considered, and the strong correlation between $E_{i}$ and $D_{i} / D_{S i}$, suggests that $D_{i} /$ $D_{S i}$ is an excellent predictor of the magnitude of the isotope effect in silicate liquids.

The observed range in $D_{i} / D_{S i}$ and its explanation have been described previously (Dingwell, 1990) and it has been shown that $D_{i} / D_{S i}$ generally increases with increasing liquid viscosity $\eta$ (cf. Dingwell, 2006). The reason that $D_{i} / D_{S i}$ is lower in the AB-DI system than in the AB-AN system can be attributed to the sensitivity of $\eta$ to changes in bulk composition. Generally, the addition of network modifying cations such as $\mathrm{Ca}$ and $\mathrm{Mg}$ lowers viscosity by forming nonbridging oxygen bonds that reduce the average interconnectivity of Si-O structures (e.g., Zhang et al., 2009). The average viscosity calculated from the model of Hui and Zhang (2007) is lower in the AB-DI system ( $\left.\eta_{\text {avg }} \approx 800 \mathrm{~Pa} \mathrm{~s}\right)$ than in the $\mathrm{AB}-\mathrm{AN}$ system $\left(\eta_{\text {avg }} \approx 6300 \mathrm{~Pa}\right.$ s) due to the former having a greater abundance of network-modifying cations $(\mathrm{CaO}+\mathrm{MgO} \approx 3.3 \mathrm{wt} \%$ versus $\mathrm{CaO} \approx 1.5 \mathrm{wt} \%$, respectively). The observation that $D_{C a} / D_{S i}$ is greater in the $\mathrm{AB}-\mathrm{AN}$ system is therefore consistent with previously observed trends, and we can now see that the isotope effects follow logically, at least at a qualitative level. 


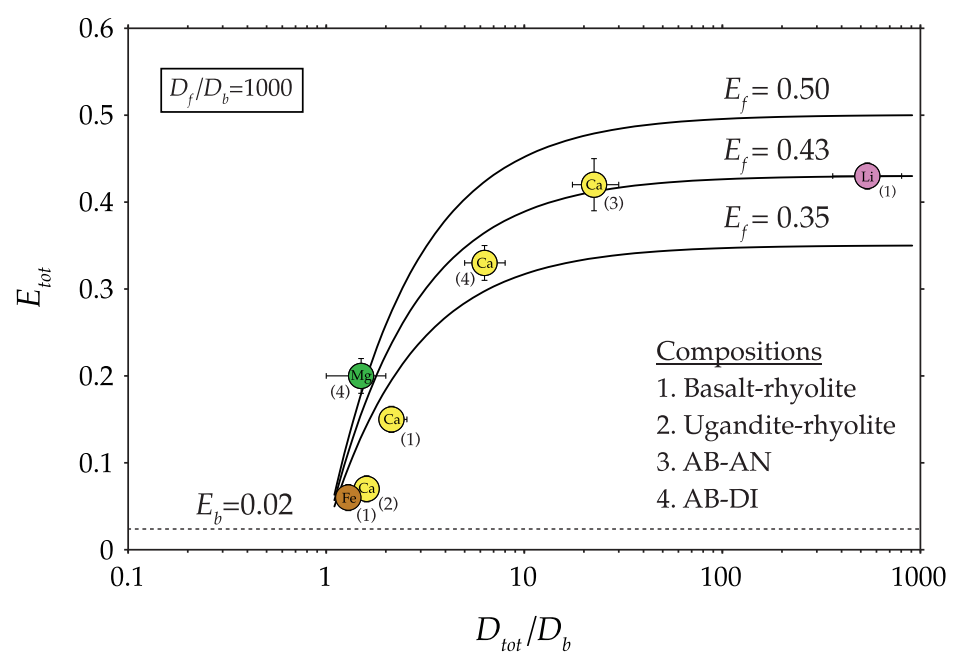

Fig. 4. The observed relationship between the efficiency of isotope separation $E_{t o t}$ (or $\left.E_{i}\right)$ and the mobility of the diffusing solute element $\left(D_{t o t}\right.$ or $\left.D_{i}\right)$ relative to the mobility of the silicate liquid matrix $\left(D_{b}\right.$ or $\left.D_{S i}\right)$. The error bars shown are estimates and have slightly different meanings for different sets of data. In the natural silicate liquid experiments (compositions 1 and 2), the diffusion couples used spanned a large range of liquid compositions, including a large range of $\mathrm{SiO}_{2}$ concentration. Because the diffusivities are a function of $\mathrm{SiO}_{2}$, the $D_{i} / D_{S i}$ values shown are referenced to a particular value of $66 \mathrm{wt} \% \mathrm{SiO}_{2}$; and the error bars include how $D_{i} / D_{S i}$ varies over the range from 61 to $71 \mathrm{wt} \% \mathrm{SiO}_{2}$. For the $\mathrm{AB}-\mathrm{AN}$ and $\mathrm{AB}-\mathrm{DI}$ compositions (3 and 4), the $\mathrm{SiO}_{2}$ content has minimal variability and is close to $66 \mathrm{wt} \% \mathrm{SiO}_{2}$. $\mathrm{However}$, for these compositions, the $x$-error bars do not include the relatively large uncertainties in $D_{S i}$. The model curves show the expected relationship between the efficiency of isotope separation and the normalized diffusivity for different values of $E_{f}$ (see Eqs. (11) and (12)). The model views the cation as being partitioned between two species - one that is strongly bound and one that is weakly bound to the liquid matrix - such that the diffusivity is the sum of two mechanisms of transport: (1) site-hopping among and (2) translating or rotating with larger aluminosilicate matrix units. The net diffusivity $\left(D_{t o t}\right)$ and net efficiency of isotope separation $\left(E_{t o t}\right)$ depends on how the cation is partitioned between species. The curves shown are for a single value of $D_{f} / D_{b}=1000$. The lower bound of $E_{b}=0.02$ is comparable to the value of $E<0.05$ inferred for Ge (used as an analog for $\mathrm{Si}$ ) in $\mathrm{GeO}_{2}$ (Richter et al., 1999).

The relationship between $E_{i}$ and $D_{i} / D_{S i}$ can be understood in terms of the strength of solute-solvent interactions. In the situation where the diffusivity of an element (like $\mathrm{Li}$ in natural liquids, or $\mathrm{Ca}$ in the $\mathrm{AB}-\mathrm{AN}$ experiment) is much greater than the diffusivity of $\mathrm{Si}$, it is likely that the element is not strongly bound to the aluminosilicate matrix, and hence is diffusing mostly as an isolated atom through a quasi-stationary aluminosilicate framework. This condition results in the large mass discrimination between isotopes of $\mathrm{Li}$ in natural silicate liquids and $\mathrm{Ca}$ in albitic liquids. For elements like $\mathrm{Ca}, \mathrm{Mg}$, and $\mathrm{Fe}$ in basaltic liquids, where the diffusivities are approximately the same as that of $\mathrm{Si}$, these elements must be more strongly bound to the aluminosilicate matrix and hence are diffusing effectively as part of more massive multi-atom complexes that include $\mathrm{Si}$.

\subsection{Model for diffusive isotope effects in silicate liquids}

The goal in this section is to describe an idealized quantitative model that can account for the relationship between $E_{i}$ and $D_{i} / D_{S i}$ in silicate liquids. The main idea behind our approach is that the chemical diffusivity and its mass dependence represent the sum of two (or possibly more) distinct mechanisms of transport (Bryce et al., 1999): site-hopping among, and translating or rotating with, larger aluminosilicate structures in the melt. To represent these two diffusion mechanisms, we depict an element such as $\mathrm{Ca}$ as being partitioned between two distinct chemical species - one that is relatively mobile $\left(\mathrm{Ca}_{\mathrm{f}}\right)$ and one in which $\mathrm{Ca}$ is no more mo- bile than the matrix itself $\left(\mathrm{Ca}_{\mathrm{b}}\right)$. Hereafter we refer to these two species using the subscripts $f$ for "free" and $b$ for "bound", respectively.

$$
\begin{gathered}
\text { "Free" } \mathrm{Ca}\left(\mathrm{Ca}_{f}\right) \\
\mathrm{Ca}_{f} \mathrm{O}+[\equiv(\mathrm{Si}, \mathrm{Al})-\mathrm{O}-(\mathrm{Si}, \mathrm{Al}) \equiv] \longleftrightarrow\left[\equiv(\mathrm{Si}, \mathrm{Al})-\mathrm{O}{ }_{\mathrm{Ca}_{b}} \mathrm{O}-(\mathrm{Si}, \mathrm{Al}) \equiv\right]
\end{gathered}
$$

This model views the silicate liquid as if it were a liquid ion exchange resin having a large molecular weight. $\mathrm{Ca}$ is partitioned between the "free" form and the "bound" form, and it is assumed that the rate of exchange between free and bound phases is infinitely fast (i.e., local equilibrium applies). The diffusivity of $\mathrm{Ca}$ will be determined by the partition coefficient $\left(K=\mathrm{Ca}_{\mathrm{b}} / \mathrm{Ca}_{\mathrm{f}}\right)$. If the isotopic dependence of diffusivity is different for the free and bound species, then there will be a correlation between $E_{C a}$ and $D_{C a}$, or between $E_{C a}$ and $D_{C a} / D_{\text {matrix }}$.

To derive the relationship that follows from this model, we begin with the total flux of the element, which is the sum of the flux of each of the species:

$J_{\text {tot }}=J_{f}+J_{b}$.

Using Fick's First Law, this can be expressed for onedimensional diffusion as

$D_{t o t} \frac{\partial C_{t o t}}{\partial x}=D_{f} \frac{\partial C_{f}}{\partial x}+D_{b} \frac{\partial C_{b}}{\partial x}$, 
where $C_{t o t}$ is the total concentration, $C_{f}$ is the concentration of species $f$ and $C_{b}$ is the concentration of species $b$. Substituting $C_{b}=K C_{f}$ and $C_{\text {tot }}=(1+K) C_{f}$, into Eq. (9) leads to an expression for the net diffusivity (assuming $K$ is constant):

$D_{t o t}=\frac{D_{f}+K D_{b}}{1+K}$,

The equation for the normalized diffusivity is

$\frac{D_{t o t}}{D_{b}}=\frac{D_{f}+K D_{b}}{D_{b}(1+K)}$.

Finally, the ratio of the diffusivities of two isotopes $i$ and $j$ is

$\frac{D_{t o t, i}}{D_{t o t, j}}=\frac{D_{f, i}+K_{i} D_{b, i}}{D_{f, j}+K_{j} D_{b, j}} \cdot \frac{1+K_{j}}{1+K_{i}}$.

Fig. 4 shows the expected relationship between $E$ from Eq. (12) and the normalized diffusivity from Eq. (11). There are three input parameters: (1) $D_{f} / D_{b}$, (2) $E_{f}$ for $D_{f}$ and (3) $E_{b}$ for $D_{b}$, each of which is fixed and then $K$ is varied to generate the model curve. For this initial evaluation of the model, we assume there is no isotopic partitioning between species $\left(K_{i}=K_{j}\right)$. The intriguing result is that this simplified picture of chemical diffusion leads to a relationship between $D_{\text {tot }} / D_{b}$ and $E_{\text {tot }}$ that is similar to what is observed in the data; for $1<D_{t o t} / D_{b}<10, E_{t o t}$ varies significantly, and for $D_{\text {tot }} / D_{b}>10, E_{\text {tot }}$ is relatively constant. The curve depends somewhat on the input parameters, which may be different for each isotope system as well as each bulk composition. An important question is whether $E_{f}$ and $E_{b}$ (which represent the upper and lower limits to $E_{\text {tot }}$ in this model) can be assumed to be equivalent for different elements and compositions. If so, and assuming the ratio $D_{f} / D_{b}$ were known for a given cation and composition, then the observed relationship between the normalized diffusivity and efficiency of isotope separation across different systems could be interpreted in terms of the relative abundance $K$ of the "free" versus "bound" species. There is some information on $D_{f} f$ $D_{b}$, but only for $\mathrm{CO}_{2}$ and only in a limited number of com- positions (Nowak et al., 2004). Assuming $D_{f} / D_{b}=1000$ and $E_{f}=0.43$ for $\mathrm{Ca}$ in albitic liquid, a value of $E_{t o t}=0.36$ would indicate that $K \approx 27$ for the Ca-bearing species. It is unclear, however, whether this model represents an adequate description of the diffusion process and the observed relationship between $D_{t o t} / D_{b}$ and $E_{t o t}$. It may be the case that a more complicated model is warranted or that other parameters may be important. For example, the timescale of exchange between species may not be sufficiently short to warrant the local equilibrium approximation, and if the kinetics of exchange are important, the rate of exchange for the lighter isotope may be faster than that for the heavier isotope.

\subsection{Comparison to aqueous solutions}

The relationship between diffusivity and the efficiency of isotope separation by diffusion may be applicable to other non-molecular liquids. Fig. 5 combines results from silicate liquid experiments with results from experiments on cation diffusion in aqueous solutions. To generalize the terminology we plot $E_{\text {solute }}$ versus the ratio $D_{\text {solute }} / D_{\text {solvent }}$ where the solvent is $\mathrm{H}_{2} \mathrm{O}$ in the aqueous solution case and the aluminosilicate matrix in the silicate liquid case. For $D_{\text {solvent }}$ we use the self-diffusion coefficient of $\mathrm{H}_{2} \mathrm{O}$ (Bourg and Sposito, 2007) and the measured diffusion coefficient of Si. For the aqueous solutions, $\mathrm{D}_{\mathrm{H}_{2} \mathrm{O}}$ is constant for a given temperature, so the data indicate that there is a correlation between $E$ and diffusivity of the solute. For the silicate liquids, $D_{S i}$ is variable so there is not a one-to-one correspondence between $D_{\text {solute }}$ and $D_{\text {solute }} / D_{\text {solvent }}$. A summary of the data used in the compilation of Fig. 5 is provided in Table 3.

In the case of ions in aqueous solution, recent studies offer a molecular scale explanation of the pattern shown in Fig. 5. The efficiency of isotope separation for a cation (and its diffusivity) correlates with the residence time of water molecules in its first solvation shell as determined from molecular dynamics simulations (Bourg and Sposito, 2007, 2008; Bourg et al., 2010). If the water molecules are

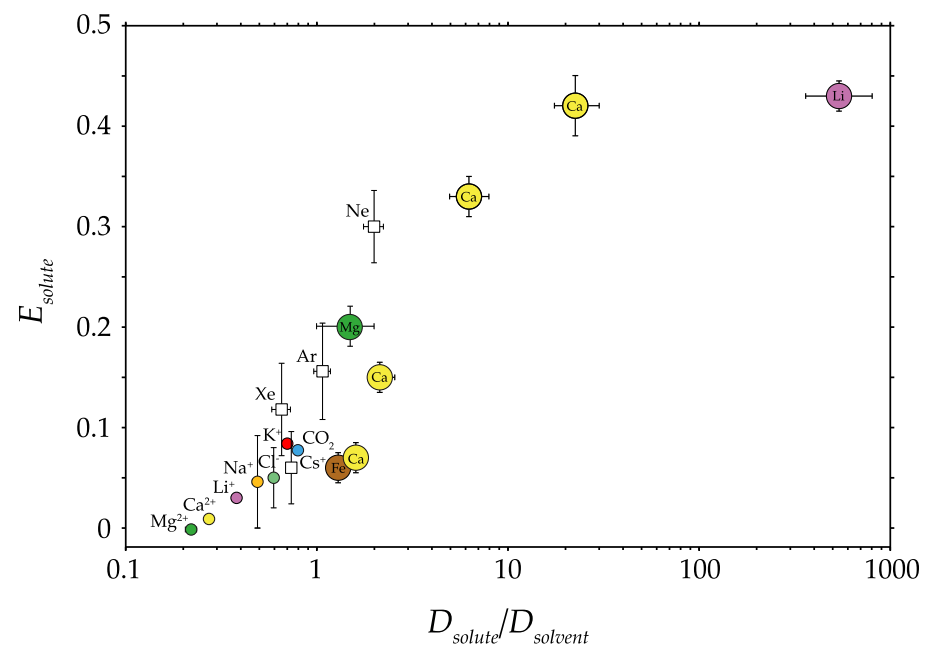

Fig. 5. The efficiency of isotope separation $E$ in silicate liquids (large symbols) compared to $E$ in aqueous solutions (small symbols). The subscript solvent refers to $\mathrm{H}_{2} \mathrm{O}$ in aqueous solutions and $\mathrm{Si}\left(\right.$ or $\left.\mathrm{SiO}_{2}\right)$ in silicate liquids. Square symbols represent values obtained solely from molecular dynamics simulations (see Table 3 for complete summary). 
Table 3

Summary of the values and associated references used in the compilation of Fig. 5.

\begin{tabular}{|c|c|c|c|c|c|c|c|c|c|c|}
\hline Diffusing medium & $\begin{array}{l}\text { Experiment } \\
\text { No. }\end{array}$ & Description & $\begin{array}{l}\text { Isotopic } \\
\text { system }\end{array}$ & $\begin{array}{l}D_{\text {solute }} \\
\left(\mathrm{m}^{2} / \mathrm{s}\right)\end{array}$ & $(+/-)$ & $\begin{array}{r}D_{\text {solvent }} \\
\left(\mathrm{m}^{2} / \mathrm{s}\right)\end{array}$ & $(+/-)$ & $E$ & $(+/-)$ & References \\
\hline Natural volcanic liquids & $\begin{array}{l}\text { DF-9 } \\
\text { RB-2 } \\
\text { RB-X } \\
\text { RB-5 } \\
\text { RB-X }\end{array}$ & $\begin{array}{l}\text { basalt-rhyolite } \\
\text { basalt-rhyolite } \\
\text { basalt-rhyolite } \\
\text { basalt-rhyolite } \\
\text { basalt-rhyolite }\end{array}$ & $\begin{array}{l}{ }^{44} \mathrm{Ca} /{ }^{40} \mathrm{Ca} \\
{ }^{44} \mathrm{Ca} /{ }^{40} \mathrm{Ca} \\
{ }^{26} \mathrm{Mg} /{ }^{24} \mathrm{Mg} \\
{ }^{7} \mathrm{Li} /{ }^{6} \mathrm{Li} \\
{ }^{56} \mathrm{Fe} /{ }^{54} \mathrm{Fe}\end{array}$ & $\begin{array}{l}3.60 \mathrm{E}-12 \\
1.30 \mathrm{E}-11 \\
- \\
3.20 \mathrm{E}-09 \\
1.40 \mathrm{E}-11\end{array}$ & $\begin{array}{l}- \\
- \\
- \\
- \\
-\end{array}$ & $\begin{array}{l}2.30 \mathrm{E}-12 \\
5.90 \mathrm{E}-12 \\
1.10 \mathrm{E}-11 \\
5.90 \mathrm{E}-12 \\
1.10 \mathrm{E}-11\end{array}$ & $\begin{array}{l}- \\
- \\
- \\
- \\
-\end{array}$ & $\begin{array}{l}0.07 \\
0.15 \\
0.10 \\
0.43 \\
0.06\end{array}$ & $\begin{array}{l}(0.01) \\
(0.01) \\
(0.01) \\
(0.01) \\
(0.01)\end{array}$ & $\begin{array}{l}\text { Watkins et al. (2009) } \\
\text { Richter et al. (2003) } \\
\text { Richter et al. (2008) } \\
\text { Richter et al. (2003) } \\
\text { Richter et al. (2009) }\end{array}$ \\
\hline Simple silicate liquids & $\begin{array}{l}\mathrm{AB}-\mathrm{AN} \\
\mathrm{AB}-\mathrm{DI} \\
\mathrm{AB}-\mathrm{DI}\end{array}$ & $\begin{array}{l}\text { albite }+ \text { anorthite } \\
\text { albite }+ \text { diopside } \\
\text { albite }+ \text { diopside }\end{array}$ & $\begin{array}{l}{ }^{44} \mathrm{Ca} /{ }^{40} \mathrm{Ca} \\
{ }^{44} \mathrm{Ca} /{ }^{40} \mathrm{Ca} \\
{ }^{26} \mathrm{Mg} /{ }^{24} \mathrm{Mg}\end{array}$ & $\begin{array}{l}4.50 \mathrm{E}-11 \\
2.50 \mathrm{E}-11 \\
6.00 \mathrm{E}-12\end{array}$ & $\begin{array}{l}- \\
- \\
-\end{array}$ & $\begin{array}{l}2.00 \mathrm{E}-12 \\
4.00 \mathrm{E}-12 \\
4.00 \mathrm{E}-12\end{array}$ & $\begin{array}{l}- \\
- \\
-\end{array}$ & $\begin{array}{l}0.42 \\
0.33 \\
0.20\end{array}$ & $\begin{array}{l}(0.03) \\
(0.02) \\
(0.02)\end{array}$ & $\begin{array}{l}\text { This study } \\
\text { This study } \\
\text { This study }\end{array}$ \\
\hline Diffusing medium & Experiment No. & Description & Isotopic system & & & & & $E$ & & References \\
\hline Liquid water $\left(25^{\circ} \mathrm{C}\right)$ & $\begin{array}{l}- \\
- \\
- \\
-\end{array}$ & $\begin{array}{l}\text { MD simulation } \\
\text { MD simulation } \\
\text { MD simulation } \\
\text { MD simulation }\end{array}$ & $\begin{array}{l}\mathrm{He} \\
\mathrm{Ne} \\
\mathrm{Ar} \\
\mathrm{Xe}\end{array}$ & $\begin{array}{l}7.85 \mathrm{E}-09 \\
4.78 \mathrm{E}-09 \\
2.57 \mathrm{E}-09 \\
1.57 \mathrm{E}-09\end{array}$ & $\begin{array}{l}(0.54) \\
(0.37) \\
(0.57) \\
(0.11)\end{array}$ & $\begin{array}{l}2.40 \mathrm{E}-09 \\
2.40 \mathrm{E}-09 \\
2.40 \mathrm{E}-09 \\
2.40 \mathrm{E}-09\end{array}$ & $\begin{array}{l}(0.10) \\
(0.10) \\
(0.10) \\
(0.10)\end{array}$ & $\begin{array}{l}0.342 \\
0.300 \\
0.156 \\
0.118\end{array}$ & $\begin{array}{l}(0.056) \\
(0.036) \\
(0.048) \\
(0.046)\end{array}$ & $\begin{array}{l}\text { Bourg and Sposito (2008) } \\
\text { Bourg and Sposito (2008) } \\
\text { Bourg and Sposito (2008) } \\
\text { Bourg and Sposito (2008) }\end{array}$ \\
\hline Liquid water $\left(75^{\circ} \mathrm{C}\right)$ & $\begin{array}{l}- \\
- \\
- \\
- \\
- \\
- \\
- \\
- \\
- \\
- \\
-\end{array}$ & $\begin{array}{l}\text { Experiment } \\
\text { Experiment } \\
\text { Experiment } \\
\text { MD simulation } \\
\text { Experiment } \\
\text { MD simulation } \\
\text { Experiment } \\
\text { MD simulation } \\
\text { MD simulation } \\
\text { Experiment } \\
\text { MD simulation }\end{array}$ & $\begin{array}{l}{ }^{25} \mathrm{Mg} /{ }^{24} \mathrm{Mg} \\
{ }^{7} \mathrm{Li} /{ }^{6} \mathrm{Li} \\
{ }^{37} \mathrm{Cl} /{ }^{35} \mathrm{Cl} \\
\mathrm{Na} \\
{ }^{24} \mathrm{Na} /{ }^{22} \mathrm{Na} \\
\mathrm{K} \\
{ }^{41} \mathrm{~K} /{ }^{39} \mathrm{~K} \\
\mathrm{Cs} \\
\mathrm{Ca} \\
{ }^{44} \mathrm{Ca} /{ }^{40} \mathrm{Ca} \\
\mathrm{Li}\end{array}$ & $\begin{array}{l}1.21 \mathrm{E}-09 \\
2.09 \mathrm{E}-09 \\
3.27 \mathrm{E}-09 \\
2.69 \mathrm{E}-09 \\
- \\
3.85 \mathrm{E}-09 \\
- \\
4.04 \mathrm{E}-09 \\
1.50 \mathrm{E}-09 \\
- \\
2.12 \mathrm{E}-09\end{array}$ & $\begin{array}{l}(0.06) \\
(0.08) \\
(0.14) \\
(0.14) \\
- \\
(0.17) \\
- \\
(0.20) \\
(0.03) \\
- \\
(0.08)\end{array}$ & $\begin{array}{l}5.50 \mathrm{E}-09 \\
5.50 \mathrm{E}-09 \\
5.50 \mathrm{E}-09 \\
5.50 \mathrm{E}-09 \\
- \\
5.50 \mathrm{E}-09 \\
- \\
5.50 \mathrm{E}-09 \\
5.50 \mathrm{E}-09 \\
- \\
5.50 \mathrm{E}-09\end{array}$ & $\begin{array}{l}(0.10) \\
(0.10) \\
(0.10) \\
(0.10) \\
- \\
(0.10) \\
- \\
(0.10) \\
(0.10) \\
- \\
(0.10)\end{array}$ & $\begin{array}{l}0.000 \\
0.030 \\
0.050 \\
0.058 \\
0.046 \\
0.098 \\
0.084 \\
0.060 \\
0.000 \\
0.009 \\
0.034\end{array}$ & $\begin{array}{l}(0.003) \\
(0.004) \\
(0.030) \\
(0.044) \\
(0.046) \\
(0.034) \\
(0.004) \\
(0.036) \\
(0.022) \\
(0.001) \\
(0.032)\end{array}$ & $\begin{array}{l}\text { Richter et al. (2006); Bourg and Sposito (2007) } \\
\text { Richter et al. (2006); Bourg and Sposito (2007) } \\
\text { Richter et al. (2006); Bourg and Sposito (2007) } \\
\text { Bourg et al. (2010) } \\
\text { Pikal (1972) } \\
\text { Bourg et al. (2010) } \\
\text { Bourg et al. (2010) } \\
\text { Bourg et al. (2010) } \\
\text { Bourg et al. (2010) } \\
\text { Bourg et al. (2010) } \\
\text { Bourg et al. (2010) }\end{array}$ \\
\hline Liquid water $\left(25^{\circ} \mathrm{C}\right)$ & - & $\begin{array}{l}\text { Experiment } \\
\text { Experiment }\end{array}$ & $\begin{array}{l}{ }^{13} \mathrm{CO}_{2} /{ }^{12} \mathrm{CO}_{2} \\
{ }^{4} \mathrm{He} /{ }^{3} \mathrm{He}\end{array}$ & $\begin{array}{l}1.91 \mathrm{E}-09 \\
7.22 \mathrm{E}-09\end{array}$ & $\begin{array}{l}(0.27) \\
(0.73)\end{array}$ & $\begin{array}{l}2.40 \mathrm{E}-09 \\
2.40 \mathrm{E}-09\end{array}$ & $\begin{array}{l}(0.10) \\
(0.10)\end{array}$ & $\begin{array}{l}0.077 \\
0.97\end{array}$ & $\begin{array}{l}(0.004) \\
(0.18)\end{array}$ & $\begin{array}{l}\text { Jähne et al. (1987) } \\
\text { Jähne et al. (1987) }\end{array}$ \\
\hline
\end{tabular}


weakly bound, as for $\mathrm{Li}^{+}$, it implies that the ion can move through the liquid as a single atom and therefore the mass dependence of the diffusivity is more strongly influenced by the relative mass difference of the isotopes. If a number of water molecules are strongly bound to the ion, the effective mass of the diffusing species is larger than that of the ion, and the mass dependence of the diffusivity is highly attenuated. Since the hydration shell is dynamic, the actual situation is that the ion spends part of the time isolated and part of the time bound to water molecules. If the hydration shell is massive enough, and the lifetime of the water molecules in the hydration shell long enough, the isotopic effect tends toward zero, as seems to be the case for aqueous $\mathrm{Mg}^{2+}$. For the other ions the mass dependence of the diffusivity is nonzero, but much smaller than the inverse square root of the isotopic masses $(E=1)$. It should be noted that in the cases of $\mathrm{Mg}^{2+}, \mathrm{Ca}^{2+}, \mathrm{K}^{+}$, and $\mathrm{Li}^{+}$, the ratio of the diffusion coefficients for the isotopes has been measured experimentally, whereas the lifetime of water molecules in the hydration shell has been estimated using molecular dynamics models.

An important difference between aqueous solutions and silicate liquids is that ions in aqueous solution typically diffuse more slowly than $\mathrm{H}_{2} \mathrm{O}$, whereas elements in silicate liquids diffuse faster than $\mathrm{Si}$. For aqueous solutions this effect may be due to charge balance constraints in addition to hydration, and the fact that water molecules are weakly bound to each other. In silicate liquids, $\mathrm{Si}$ is strongly bound in multi-atom complexes with $\mathrm{O}$ (as well as $\mathrm{Al}$ and other $\mathrm{Si}$ atoms), so it diffuses more slowly than other elements. The average size and lifetime of these $\mathrm{Si}-\mathrm{O}$ complexes varies with liquid composition and could account for the variations in $D_{S i}$.

\subsection{Other quantitative parameters}

The parameter $D_{\text {solute }} / D_{\text {solvent }}$ is convenient in that it can be determined by experiment, but other parameters, particularly those at the molecular scale, may provide additional insight. Molecular dynamics simulations are increasingly used to study the structure and dynamics of silicate melts (Vuilleumier et al., 2009; de Koker and Stixrude, 2010; Karki, 2010). For example, solute diffusivity as well as the efficiency of isotope separation could be related to (1) the average lifetime of solute-matrix bonds $\left(\tau_{\text {solute-Si }}, \tau_{\text {solute-O}}\right)$, (2) the mutual-diffusion coefficients (Wheeler and Newman, 2004) of the solute with individual elements of the Al-Si network such as $\mathrm{AlO}_{4}$ tetrahedra, (3) the interconnectivity of the Al-Si network or relative proportions of $Q^{n}$ species, where $Q$ refers to an $\mathrm{SiO}_{4}$ tetrahedron connected by a bridging oxygen atom to $n$ adjacent $\mathrm{SiO}_{4}$ tetrahedra, or (4) the dynamics of the Al-Si network itself, which could be approximated as the average lifetime of bridging oxygen bonds $\left(\tau_{S i-O}\right)$ and would represent the exchange rate of $Q^{n}$ species. Essentially, these parameters express the nanometer-scale coupling of solute and solvent motions on time scales that range from rapid solute-solvent collisions to slow reorganizations of the $\mathrm{Al}-\mathrm{Si}$ network. Theoretical and MD simulation studies indicate that in simple (hardsphere or Lennard-Jones) fluids and in liquid water, the efficiency of isotope separation $E$ decreases as solute-sol- vent coupling increases (Bhattacharyya and Bagchi, 2000; Bourg et al., 2010).

To our knowledge, there are no MD studies on silicate liquids in which isotope-specific diffusivities have been reported. Additionally, due to computational constraints (cf. Karki, 2010) most MD simulations on silicate liquids are carried out at temperatures that far exceed those of our experiments (typically $3000-6000 \mathrm{~K}$ ). It is nevertheless worthwhile to consider how MD studies may provide a more detailed understanding of the mechanisms of diffusive isotope separation in silicate liquids.

In a study that simulates relatively low temperatures (1827-3727 ${ }^{\circ} \mathrm{C} ; P \approx 1 \mathrm{GPa}$ ), Horbach et al. (2001) investigated the structure and dynamics of Na-silicate melts $\left(\mathrm{Na}_{2}\right.$ $\mathrm{Si}_{2} \mathrm{O}_{5}, \mathrm{Na}_{2} \mathrm{Si}_{3} \mathrm{O}_{7}$, and $\mathrm{SiO}_{2}$ ). $\mathrm{Na}$ was found to diffuse rapidly and the ratio $D_{N a} / D_{S i}$ was large for all conditions studied $\left(\approx 100\right.$ at $1827^{\circ} \mathrm{C}$ and down to $\approx 5$ at $\left.3727^{\circ} \mathrm{C}\right)$. The diffusivity of $\mathrm{Na}, \mathrm{Si}$, and $\mathrm{O}$ were compared to the average lifetime of chemical bonds $\left(\tau_{\alpha-\beta}\right)$ between atoms of type $\alpha$ and $\beta$. The mobility of $\mathrm{Na}$ atoms is not correlated with the lifetime of $\mathrm{Na}-\mathrm{O}$ or $\mathrm{Na}-\mathrm{Si}$ bonds, but rather with the lifetime of $\mathrm{Na}-\mathrm{Na}$ bonds, suggesting that the elementary diffusion step for $\mathrm{Na}$ is the breaking of $\mathrm{Na}-\mathrm{Na}$ bonds (Horbach et al., 2001). This conclusion is consistent with a model where $\mathrm{Na}$ atoms diffuse by site-hopping among $\mathrm{Na}$ "sites" in a static $\mathrm{Si}-\mathrm{O}$ matrix. In this end-member regime we would expect $E_{\alpha}$ to be large. The behavior of $\mathrm{Si}$ was found to be more complicated; there is no direct relationship between $D_{S i}$ and the lifetime of $\mathrm{Si}-\mathrm{O}$ or $\mathrm{Si}-\mathrm{Si}$ bonds (Horbach et al., 2001). The data in Fig. 4 indicate that $D_{\alpha} / D_{S i}$ and $E_{\alpha}$ co-vary, but we cannot discern whether they are responding to differences in the relative lifetimes of chemical bonds (e.g., $\tau_{S i-S i} / \tau_{\alpha-S i}$ ), other parameters such as $Q^{n}$ speciation, or a combination.

\subsection{Geological implications}

It is now recognized that discernible isotope effects can be produced by chemical diffusion in molten silicates. This result and the recent discovery of temperature-induced fractionations (Richter et al., 2008, 2009; Huang et al., 2010) suggest that there is considerable stable isotopic variability in igneous systems. A number of recent studies have documented these effects and have used them to assess the role of diffusion and extent of isotopic disequilibrium during crystallization (Teng et al., 2008a), subsolidus cooling (Barrat et al., 2005; Beck et al., 2006; Dauphas et al., 2010), thermal migration (Lundstrom, 2009) and wallrock contamination (Teng et al., 2006, 2008b; Chopra et al., 2009). Future studies will undoubtedly uncover additional isotopic heterogeneity in igneous rocks, and interpreting these effects quantitatively will require simplified physical models and knowledge of the magnitude of $E_{\text {solute }}$ and how it varies with temperature, pressure, and composition (e.g., Beck et al., 2006; Dauphas et al., 2010).

The correlation of $E_{\text {solute }}$ with $D_{\text {solute }} / D_{\text {solvent }}$ offers a useful empirical relationship for predicting where there may be large isotope effects in nature. An important conclusion is that $D_{\text {solute }} / D_{\text {solvent, }}$ and $E_{\text {solute }}$ are likely to be greater in high- $\mathrm{SiO}_{2}$ liquids than in low- $\mathrm{SiO}_{2}$ liquids and with decreas- 
ing temperature toward the glass transition (Dingwell, 1990). Watson and Müller (2009) modeled the expected effects of diffusive isotopic fractionations of trace elements incorporated during the growth of magmatic crystals. They show the expected isotopic profiles within and around crystals for different values of $E$, crystal growth rate and fluid velocity. For ${ }^{44} \mathrm{Ca} /{ }^{40} \mathrm{Ca}$, a diffusivity difference of $1 \%$ $(E=0.21)$, which may be a reasonable value for a rhyolitic liquid, can lead to fractionations of $4 \%$ for a cm-sized crystal in a stagnant fluid. This value assumes that equilibrium as well as surface reaction effects are negligible, which may or may not be the case. Models such as this provide a useful foundation for future comparison to actual measurements; at present there are few (if any) on mass-dependent isotope effects in igneous minerals at the sub-grain scale. Our experimental results also indicate that even for a given bulk composition, different cations may have significantly different values of $E$ and therefore different isotope pairs may be sensitive as recorders of crystallization conditions during different stages of magmatic differentiation.

\section{SUMMARY AND CONCLUSIONS}

Superliquidus diffusion-couple experiments using simplified synthetic silicate liquids were carried out to investigate why the efficiency of isotope separation by diffusion varies between cations and in liquids of different composition. Two diffusion experiments were conducted using combinations of the mineral constituents albite, anorthite and diopside. For both experiments, a simplified chemical diffusion model was used to estimate cation diffusivities $\left(D_{\text {cation }}\right)$ and the efficiency of isotope separation $(E)$.

The experimental results indicate that a relationship exists between the efficiency of isotope separation $E$ and the normalized diffusivity - the ratio of the mobility of the cation $\left(D_{\text {cation }}\right)$ to the mobility of the liquid matrix $\left(D_{S i}\right)$. Where $D_{\text {cation }} \leqslant D_{S i}$, isotope separation by diffusion is less efficient because the cation is likely to be more strongly bound to the aluminosilicate matrix, and hence, the mass difference between isotopes is effectively reduced because the cation is associated with a larger complex that includes $\mathrm{Si}$, and its motion in the liquid is correlated with the motions of many other atoms. Conversely, where $D_{\text {cat }}$ ion $\gg D_{S i}$, isotope separation by diffusion is more efficient because it is likely that the element is not strongly bound to the aluminosilicate matrix and is diffusing mostly as an isolated atom through a quasi-stationary aluminosilicate framework.

Our results and interpretive model offer a plausible explanation for why diffusive isotope effects are greater in silicate liquids at $1450{ }^{\circ} \mathrm{C}$ than in aqueous solutions at $25-75^{\circ} \mathrm{C}$. In silicate liquids, the solvent is mainly silicon in the form of silica tetrahedra, which are generally less mobile than the other cations; that is, $D_{\text {cation }} / D_{\text {solvent }}$ is generally greater than unity. In aqueous solutions, by contrast, the solvent water molecules are generally more mobile than the diffusing ions owing to relatively strong interactions between ions and their surrounding water molecules.

The correlation of $E_{\text {solute }}$ with $D_{\text {solute }} / D_{\text {solvent }}$ offers a useful empirical relationship for estimating diffusive isotope ef- fects in geological liquids. The parameter $D_{\text {solute }} / D_{\text {solvent }}$ is convenient in that it can be determined by experiment, but it is only a proxy for how strongly bound a cation is to the liquid matrix. Other parameters may also be important, and molecular simulations should be used to further investigate isotope separation in silicate liquids.

Our empirical result also provides a context for discussing diffusive isotope effects in natural geologic environments. It is now recognized that kinetic isotope separations can be relatively large, even at the high temperatures associated with molten silicates, and our results indicate that these effects for common cations like $\mathrm{K}, \mathrm{Ca}, \mathrm{Mg}$, $\mathrm{Fe}$ and $\mathrm{Li}$, are likely to be greater in high- $\mathrm{SiO}_{2}$ liquids than in low- $\mathrm{SiO}_{2}$ liquids. At present there are only a few documented instances of diffusive isotope effects in natural rocks - mostly in mafic systems - and future stable isotope studies will doubtless uncover much more isotopic variability. Quantifying these effects will require a combination of experiments and molecular-scale modeling in order to better understand and/or characterize the efficiency of isotope separation for different isotope pairs under different conditions. This information in turn will be useful for assessing the effects of diffusion and extent of isotopic disequilibrium during crystallization, mineral dissolution, and chemical alteration on the differentiation of silicate liquids that solidify to form igneous rocks.

\section{ACKNOWLEDGMENTS}

This manuscript benefited from thoughtful and thorough reviews by Jim Van Orman, Mathieu Roskosz, and an anonymous reviewer. J.M.W. thanks Ian Bourg, Christian Huber, and Michael Manga for helpful discussions. Special thanks are also given to Tom Owens and Shaun Brown for sharing laboratory expertise. This work was partially performed under the auspices of the U.S. Department of Energy, Office of Basic Energy Sciences by the Lawrence Livermore National Laboratory under Contract Nos. DEAC02-05CH112 and DE-AC52-07NA27344, and partially supported by the Director, Office of Science, Office of Basic Energy Sciences, of the U.S. Department of Energy under Contract No. DE-AC02-05CH11231 and the National Science Foundation under Grant No. EAR 0838168.

\section{APPENDIX A}

\section{A.1. Additional comments on relating diffusivity to mass}

The simplest treatment of isotopic diffusion applies to particles in an ideal (i.e., monatomic and dilute) gas because the identity of the diffusing species is known and potential interactions between particles can be neglected. From kinetic theory the diffusivity $D$ is the product of the root mean speed $v_{r m s}$ of particles and the mean free path $l$ between collisions:

$D=l \cdot \underbrace{\left(\frac{3 R T}{m}\right)^{1 / 2}}_{v_{\text {rms }} .}$

Since $D$ varies inversely with the square root of particle mass $m$, one might anticipate from Eq. (A1) that the ratio 
of isotopic diffusion coefficients is proportional to the square root of the inverse mass ratio between the isotopes:

$\frac{D_{2}}{D_{1}}=\left(\frac{m_{1}}{m_{2}}\right)^{1 / 2}$

This is referred to as the square-root-of-mass law and is only valid for systems in which the assumptions of kinetic theory apply. In other systems such as non-dilute gases, liquids, and solids, Eq. (A2) serves as a useful reference from which to compare the mass dependence on diffusion coefficients. For example, there is a substantial literature on isotopic diffusion in solids (Schoen, 1958; Rothman and Peterson, 1965; Le Claire, 1966; Mundy et al., 1966; many others), and deviations from the square-root-of-mass law are combined with theories of lattice or vacancy diffusion to infer diffusion mechanisms (cf. Section 1.3 in Watkins et al., 2009).

In contrast to theories of diffusion in the gas or solid phase, there is no simple scaling law that describes the relationship between diffusivity and mass in liquids because isotopic substitution affects translational and rotational mobility differently (McLaughlin, 1960). When rotation does not contribute significantly to momentum transfer, molecular motion can be described by the linear equation of motion:

$F_{\alpha}=m \frac{d v_{\alpha}}{d t}$

where $F_{\alpha}$ is the net central force acting on a molecule due to the potential field of its neighbors and $v_{\alpha}$ is the linear velocity. For spherically symmetric molecules such cyclohexane and methane, and in which only central forces matter, Eq. (A3) is expected to adequately describe molecular motion and the ratio of transport coefficients has been shown to be in agreement with the square-root-of-mass law (McLaughlin, 1960). If, on the other hand, rotational motion is important for momentum transfer, the angular equation of motion is needed for describing changes in momentum due to non-central forces:

$G_{\alpha}=I_{\alpha \beta} \frac{d \omega_{\beta}}{d t}$,

where $G_{\alpha}$ is the torque on a molecule from forces due to neighboring atoms, $I_{\alpha \beta}$ is the inertia tensor, and $\omega_{\beta}$ is the angular velocity. Rotational and translational motions of molecules are not independent; a change in torque can arise from translation of a nearby molecule or a change in force can arise from rotation of nearby molecule. This translational-rotational coupling is associated with molecular anisotropy and its effect on transport coefficients depends on intermolecular forces, which are theoretically complex (Weingartner et al., 1989). Broadly speaking, however, it is clear that isotope substitution will affect $m$ and $I_{\alpha \beta}$ differently and the resulting influence on diffusion coefficients will vary depending on the importance of rotational motion. For anisotropic molecules such as water and benzene, the ratio of isotope-specific molecular diffusion coefficients does not agree with the square root of mass law but is in better agreement when mass is replaced with the principal moments of inertia (McLaughlin, 1960; Weingartner et al., 1989):
$\frac{D_{2}}{D_{1}}-\left(\frac{I_{1, \gamma}}{I_{2, \gamma}}\right)^{1 / 2}$

where $\gamma$ refers to any of the principal axes $x, y$, and $z$.

In cases where Eq. (A5) might apply, one first needs detailed information on the structure of the diffusing species. The principal moments of inertia are known or can be calculated for simple organic molecules (e.g., Holz et al., 1996) and self diffusion NMR measurements show that the isotope effect on translational and rotational diffusion tends more towards a square-root of the moment of inertia law when there is strong translation-rotation coupling (e.g., Holz et al., 1996; Hardy et al., 2001). In silicate liquids, however, the picture is not as simple because diffusion occurs through rapid chemical exchanges instead of molecular mechanisms of motion (Stebbins, 1995). In other words, even the definition of speciation in silicate liquids is ambiguous. This motivates several of the questions addressed in this study: (1) How and why does the mass dependence on diffusivity vary between cations in molten silicates? (2) How and why does the mass dependence on diffusivity depend on liquid composition? (3) Can the physical mechanisms of diffusion be inferred from the mass dependence on diffusivity in molten silicates? (4) Can the magnitude of diffusive isotope effects be predicted for a cation or liquid composition?

\section{A.2. Additional comments on multicomponent diffusion models}

When the multicomponent diffusion equation is cast in vector notation, the diffusion coefficients that relate fluxes to gradients are housed in a diffusivity matrix where the off-diagonal terms represent diffusive coupling. Since the $\mathrm{Al}, \mathrm{Si}$, and $\mathrm{Na}$ gradients are relatively small in the $\mathrm{AB}-$ $\mathrm{AN}$ and $\mathrm{AB}-\mathrm{DI}$ experiments, explicitly accounting for the off-diagonal terms and their mass-dependence would add additional free parameters without changing our interpretation or the overall pattern shown in Fig. 4.

To illustrate this point, Fig. A1 compares data from the $\mathrm{AB}-\mathrm{AN}$ experiment to model profiles calculated assuming a hypothetical, non-unique $3 \times 3$ diffusivity matrix. Model 1 assumes no mass dependence on the offdiagonal diffusivities for $\mathrm{Ca}$ whereas Model 2 assumes a mass dependence on the off-diagonal diffusivities that is equivalent to that imposed on the diagonal term. Although the multicomponent diffusion problem offers a more detailed description of the chemical fluxes in space and time and better fits to the major-element data, the isotopic profiles are similar for the $\mathrm{AB}-\mathrm{AN}$ experiment regardless of the mass-dependence on the off-diagonal terms (Model 1 versus Model 2).

The EBD approach for $\mathrm{Ca}$ and $\mathrm{Mg}$ is ultimately justified by (1) the initial conditions of the $\mathrm{AB}-\mathrm{AN}$ and $\mathrm{AB}-\mathrm{DI}$ experiments, (2) the simplicity of the EBD model and (3) the quality of the fits to the $\mathrm{Ca}$ and $\mathrm{Mg}$ data in Figs. 1-3, which show that the EBD model provides an accurate representation of the $\mathrm{Ca}$ and $\mathrm{Mg}$ chemical and isotopic fluxes and the evolution of the diffusion profiles in space and time. 


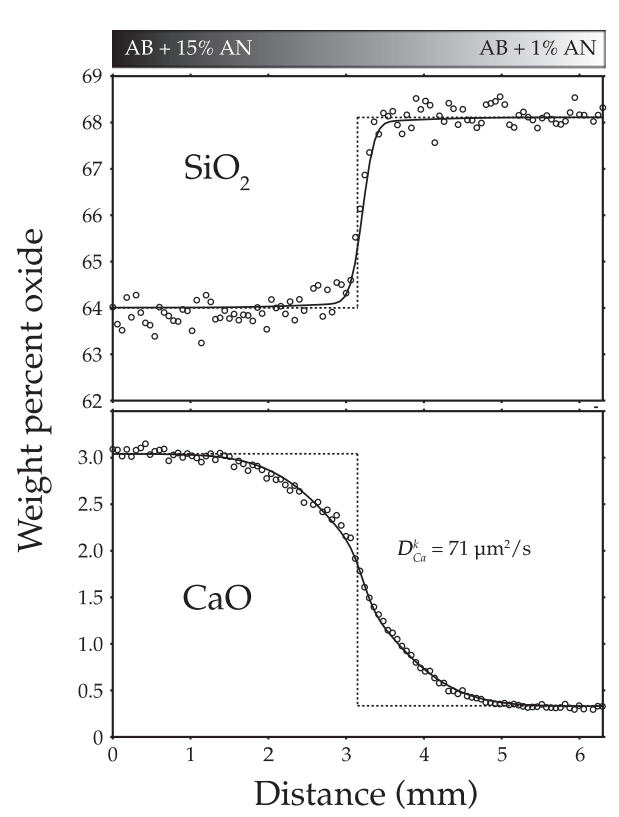

For the major-element profiles:
$[\mathbf{D}]=\mathrm{CaO}\left[\begin{array}{ccc}2 & -5 & 0 \\ -3 & 40 & -12 \\ -15 & 0 & 50\end{array}\right]$
$\mathrm{Na}_{2} \mathrm{O}_{3} \mathrm{O}$
For the $8^{44} \mathrm{Ca}$ profiles:
Model $1\left\{\begin{array}{l}E_{\mathrm{Ca}-\mathrm{Na}}=0.0 \\ E_{\mathrm{Ca}-\mathrm{Ca}}=0.42 \\ E_{\mathrm{Ca}-\mathrm{Al}}=0.0\end{array}\right.$
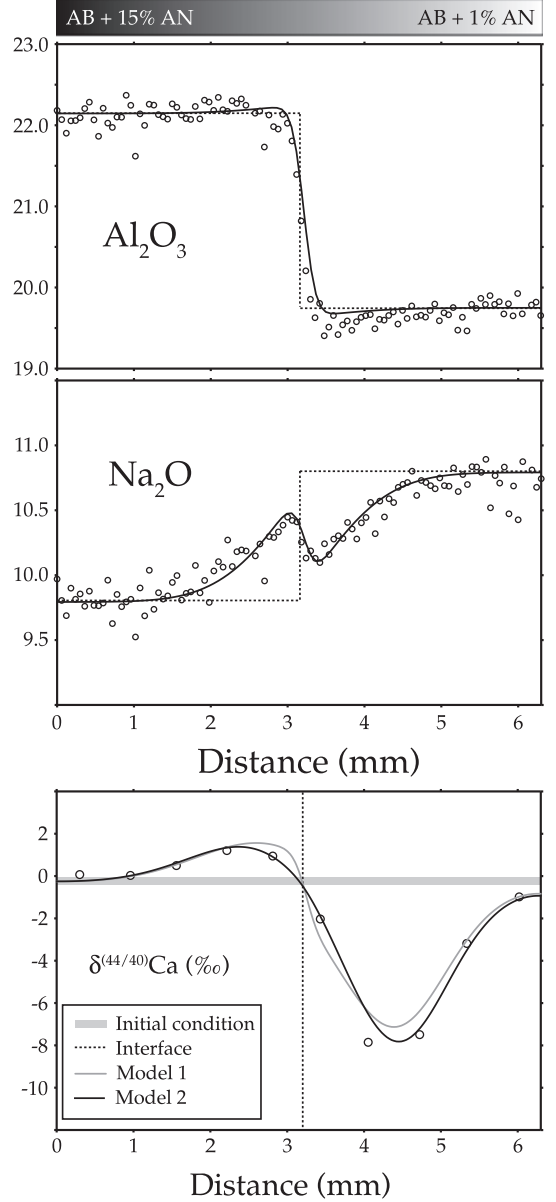

Fig. A1. Major-element profiles from the AB-AN experiment compared to model diffusion profiles (solid lines) using a hypothetical diffusivity matrix. $[\mathbf{D}]\left(\mu_{\mathrm{m}}^{2} / \mathrm{s}\right)$ was estimated from smoothed profiles of the data as inputs in MultiDIFLUX (Dayananda, 2005), and refined by trial-and-error. The lower right panel shows that the isotopic profiles are relatively insensitive to a mass-dependence on the off-diagonal terms in [D] (Model 1 versus Model 2).

\section{REFERENCES}

Baker D. (1989) Tracer versus trace element diffusion: diffusional decoupling of $\mathrm{Sr}$ concentration from $\mathrm{Sr}$ isotope composition. Geochim. Cosmochim. Acta 53, 3015-3023.

Barkan E. and Luz B. (2007) Diffusivity fractionations of $\mathrm{H}_{2}{ }^{16} \mathrm{O} /$ $\mathrm{H}_{2}{ }^{17} \mathrm{O}$ and $\mathrm{H}_{2}{ }^{16} \mathrm{O} / \mathrm{H}_{2}{ }^{18} \mathrm{O}$ in air and their implications for isotope hydrology. Rapid Commun. Mass Spectrom. 21, 2999-3005.

Barrat J., Chaussidon M., Bohn M., Gillet Ph., Göpel C. and Lesourd M. (2005) Lithium behavior during cooling of a dry basalt: an ionmicroprobe study of the lunar meteorite Northwest Africa 479 (NWA 479). Geochim. Cosmochim. Acta 69(23), 5597-5609.

Beck P., Chaussidon M., Barrat J., Gillet P. and Bohn M. (2006) Diffusion induced $\mathrm{Li}$ isotopic fractionation during the cooling of magmatic rocks: the case of pyroxene phenocrysts from nakhlite meteorites. Geochim. Cosmochim. Acta 70, 4813-4825.

Bhattacharyya K. and Bagchi B. (2000) Power law mass dependence of diffusion: a mode coupling theory analysis. Phys. Rev. E 61(4), 3850-3856.

Birch A. and LeComte P. (1960) Temperature-pressure plane for albite composition. Am. J. Sci. 258, 209-217.

Bourg I. and Sposito G. (2007) Molecular dynamics simulations of kinetic isotope fractionation during the diffusion of ionic species in liquid water. Geochim. Cosmochim. Acta 71(23), $5583-5589$.
Bourg I. and Sposito G. (2008) Isotopic fractionation of noble gases by diffusion in liquid water: molecular dynamics simulations and hydrologic applications. Geochim. Cosmochim. Acta 72, 2237-2247.

Bourg I., Richter F., Christensen J. and Sposito G. (2010) Isotopic mass dependence of metal cation diffusion coefficients in liquid water. Geochim. Cosmochim. Acta 74, 2249-2256.

Bryce J., Spera F. and Stein D. (1999) Pressure dependence of selfdiffusion in the $\mathrm{NaAlO}_{2}-\mathrm{SiO}_{2}$ system: compositional effects and mechanisms. Am. Mineral. 84, 345-356.

Chopra R., Richter F. and Watson E. (2009) Magnesium isotope fractionation by chemical diffusion in natural silicate rocks. Eos Trans. $A G U$ 90(52), V14B-05.

Dauphas N., Teng F.-Z. and Ardnt N. (2010) Magnesium and iron isotopes in $2.7 \mathrm{Ga}$ Alexo komatiite: mantle signatures, no evidence for Soret diffusion, and identification of diffusive transport in zoned olivine. Geochim. Cosmochim. Acta 74, 3274-3291.

Dayananda M. (2005) Analysis of multicomponent diffusion couples for interdiffusion fluxes and interdiffusion coefficients. J. Phase Equilib. Diffus. 26(5), 441-446.

de Koker N. and Stixrude L. (2010) Theoretical computation of diffusion in minerals and melts. Rev. Mineral. Geochem. 72, 971-991. 
DePaolo D. (2004) Calcium isotopic variations produced by biological, kinetic, radiogenic and nucleosynthetic processes. Rev. Mineral. Geochem. 55, 255-288.

Dingwell D. (1990) Effects of structural relaxation on cationic tracer diffusion in silicate melts. Chem. Geol. 82, 209-216.

Dingwell D. (2006) Transport properties of magmas: diffusion and rheology. Elements 2, 281-286.

Eiler J. (2007) "Clumped-isotope" geochemistry - the study of naturally-occurring, multiply-substituted isotopologues. Earth Planet. Sci. Lett. 262, 309-327.

Eiler J. and Shauble E. (2004) ${ }^{18} \mathrm{O}^{13} \mathrm{C}^{16} \mathrm{O}$ in Earth's atmosphere. Geochim. Cosmochim. Acta 68(23), 4767-4777.

Galy A., Yoffe O., Janney P. E., Williams R. W., Cloquet C., Alard O., Halicz L., Wadhwa M., Hutcheon I. D., Ramon E. and Carignan J. (2003) Magnesium isotope heterogeneity of the isotopic standard SRM980 and new reference materials for magnesium-isotope-ratio measurements. J. Anal. At. Spectrom. 18(11), 1352-1356.

Hardy E., Zygar A., Zeidler M., Holz M. and Sacher F. (2001) Isotope effect on the translational and rotational motion in liquid water and ammonia. J. Chem. Phys. 114(7), 3174-3181.

Holz M., Mao X. and Seiferling D. (1996) Experimental study of dynamic isotope effects in molecular liquids: detection of translation-rotation coupling. J. Chem. Phys. 104(2), 669-679.

Horbach J., Kob W. and Binder K. (2001) Structural and dynamical properties of sodium silicate melts: an investigation by molecular dynamics computer simulation. Chem. Geol. 174, 87-101.

Huang F., Chakraborty P., Lundstrom C., Holmden C., Glessner J., Kieffer S. and Lesher C. (2010) Isotope fractionation in silicate melts by thermal diffusion. Nature 464, 396-400.

Hui H. and Zhang Y. (2007) Toward a general viscosity equation for natural anhydrous and hydrous silicate melts. Geochim. Cosmochim. Acta 71, 403-416.

Jänhe B., Heinz G. and Dietrich W. (1987) Measurement of the diffusion coefficients of sparingly soluble gases in water. $J$. Geophys. Res. 92(C10), 10767-10776.

Johnson C., Beard B. and Albarede F. (2004) Geochemistry of non-traditional stable isotopes. Rev. Mineral. Geochem. 56. Mineralogical Society of America.

Karki B. (2010) First-principles molecular dynamics simulations of silicate melts: structural and dynamical properties. Rev. Mineral. Geochem. 71(1), 355-389.

Le Claire A. (1966) Some comments on the mass effect in diffusion. Philos. Mag. 14(132), 1271-1284.

Lesher C. (1990) Decoupling of chemical and isotopic exchange during magma mixing. Nature 344, 235-237.

Lesher C. (1994) Kinetics of Sr and Nd exchange in silicate liquids: theory, experiments, and applications to uphill diffusion, isotopic equilibration, and irreversible mixing of magmas. $J$. Geophys. Res. 99(B5), 9585-9604.

Liang Y. (1994) Models and Experiments for Multicomponent Diffusion in Molten Silicates, Ph.D. dissertation. University of Chicago.

Liang Y. (2010) Multicomponent diffusion in molten silicates: theory, experiments, and geological applications. Rev. Mineral. Geochem. 72, 409-443.

Lundstrom C. (2009) Hypothesis for the origin of convergent margin granitoids and Earth's continental crust by thermal migration zone refining. Geochim. Cosmochim. Acta 73, 57095729.

Luz B., Barkan E., Yam R. and Shemesh A. (2009) Fractionation of oxygen and hydrogen isotopes in evaporating water. Geochim. Cosmochim. Acta 73, 6697-6703.
McLaughlin E. (1960) Transport coefficient ratios for isotopically substituted molecules in the liquid phase and the transport mechanism. Physica 26, 650-652.

Merlivat L. (1978) Molecular diffusivities of $\mathrm{H}_{2}{ }^{16} \mathrm{O}, \mathrm{HD}^{16} \mathrm{O}$, and $\mathrm{H}_{2}{ }^{18} \mathrm{O}$ in gases. J. Chem. Phys. 69(6), 2864-2871.

Mundy J. N. et al. (1966) Sodium self-diffusion and the isotope effect. Philos. Mag. 14(130), 785-803.

Navrotsky A., Ziegler D., Oestrike R. and Maniar P. (1989) Calorimetry of silicate melts at $1773 \mathrm{~K}$ : measurement of enthalpies of fusion and of mixing in the systems diopsideanorthite-albite and anorthite-forsterite. Contrib. Mineral. Petrol. 101, 122-130.

Nowak M., Schreen D. and Spickenbom K. (2004) Argon and $\mathrm{CO}_{2}$ on the race track in silicate melts: A tool for the development of a $\mathrm{CO}_{2}$ speciation and diffusion model. Geochim. Cosmochim. Acta 68(24), 5127-5138.

Ono S., Wing B., Johnston D., Farquhar J. and Rumble D. (2006) Mass-dependent fractionation of quadruple stable sulfur isotope system as a new tracer of sulfur biogeochemical cycles. Geochim. Cosmochim. Acta 70, 2238-2252.

Pikal M. (1972) Isotope effect in tracer diffusion: comparison of the diffusion coefficients of ${ }^{24} \mathrm{Na}^{+}$and ${ }^{22} \mathrm{Na}^{+}$in aqueous electrolytes. The Journal of Physical Chemistry 76(21), 3038-3040.

Richter F., Liang Y. and Davis A. (1999) Isotope fractionation by diffusion in molten oxides. Geochim. Cosmochim. Acta 63, 2853-2861.

Richter F., Davis A., DePaolo D. and Watson E. (2003) Isotope fractionation by chemical diffusion between molten basalt and rhyolite. Geochim. Cosmochim. Acta 67, 3905-3923.

Richter F., Mendybaev R., Christensen J., Hutcheon I., Williams R. and Sturchio N. (2006) Kinetic isotope fractionation during diffusion of ionic species in water. Geochim. Cosmochim. Acta 70(2), 277-289.

Richter F., Watson E., Mendybaev R., Teng F. and Janney P. (2008) Magnesium isotope fractionation in silicate melts by chemical and thermal diffusion. Geochim. Cosmochim. Acta 72, 206-220.

Richter F., Watson E., Mendybaev R., Dauphas N., Georg B., Watkins J. and Valley J. (2009) Isotopic fractionation of the major elements of molten basalt by chemical and thermal diffusion. Geochim. Cosmochim. Acta 73, 4250-4263.

Rosalieb K. and Jambon A. (2002) Tracer diffusion of Mg, Ca, Sr, and $\mathrm{Ba}$ in Na-aluminosilicate melts. Geochim. Cosmochim. Acta 66(1), 109-123.

Rothman S. and Peterson N. (1965) Isotope effect and divacancies for self-diffusion in copper. Phys. Status Solidi 35(1), 305-312.

Schoen A. (1958) Correlation and the isotope effect for diffusion in crystalline solids. Phys. Rev. Lett. 1(4), 138-140.

Stebbins J. (1995) Dynamics and structure of silicate and oxide melts: nuclear magnetic resonance studies. Rev. Mineral. Geochem. 32(1), 191-246.

Teng F.-Z., McDonough W., Rudnick R. and Walker R. (2006) Diffusion-driven extreme lithium isotopic fractionation in country rocks of the Tin Mountain pegmatite. Earth Planet. Sci. Lett. 243, 701-710.

Teng F., Dauphas N. and Helz R. (2008a) Iron isotope fractionation during magmatic differentiation in Kilauea Iki Lava Lake. Science 320, 1620-1622.

Teng F., Rudnick R., McDonough W., Gao S., Tomascak P. and Lui Y. (2008b) Lithium isotopic composition and concentration of the deep continental crust. Chem. Geol. 255, 47-59.

Trial A. and Spera F. (1994) Measuring the multicomponent diffusion matrix: experimental design and data analysis for silicate melts. Geochim. Cosmochim. Acta 58(18), 3769-3783.

Van der Laan S., Zhang X., Kennedy A. and Wyllie P. (1994) Comparison of element and isotope diffusion of $\mathrm{K}$ and $\mathrm{Ca}$ in 
multicomponent silicate melts. Earth Planet. Sci. Lett. 123, 155-166.

Vuilleumier R., Sator N. and Guillot B. (2009) Computer modeling of natural silicate melts: what can we learn from ab initio simulations. Geochim. Cosmochim. Acta 73, 6313-6339.

Watkins J. (2010). Elemental and Isotopic Separation by Diffusion in Geological Liquids, Ph.D. dissertation. University of California, Berkeley.

Watkins J., DePaolo D., Huber C. and Ryerson F. (2009) Liquid composition-dependence of calcium isotope fractionation during diffusion in molten silicates. Geochim. Cosmochim. Acta 73, 7341-7359.

Watson E. and Müller T. (2009) Non-equilibrium isotopic and elemental fractionation during diffusion-controlled crystal growth under static and dynamic conditions. Chem. Geol. 267, 111-124.

Weingartner H., Holz M., Sacco A. and Trotta M. (1989) The effect of site-specific isotopic substitutions on transport coefficients in liquid methanol. J. Chem. Phys. 91(4), 2568-2574.

Wheeler D. and Newman J. (2004) Molecular dynamics simulations of multicomponent diffusion: 1. Equilibrium method. J. Phys. Chem. B 108, 18353-18361.
Wombacher F. et al. (2009) Separation of $\mathrm{Mg}$, Ca, and Fe from geological reference materials for stable isotope ratio analyses by MC-ICP-MS and double-spike TIMS. J. Anal. At. Spectrom. 24, 627-636.

Young E. D. and Galy A. (2004) The isotope geochemistry and cosmochemistry of magnesium. In Geochemistry of Non-Traditional Stable Isotopes (eds. C. M. Johnson, B. L. Beard and F. Albarede). Rev. Mineral. Geochem. Mineralogical Society of America, Washington, DC, pp. 197-230.

Young E., Galy A. and Nagahara H. (2002) Kinetic and equilibrium mass-dependent isotope fractionation laws in nature and their geochemical and cosmochemical significance. Geochim. Cosmochim. Acta 66(6), 1095-1104.

Zhang Y. (2010) Diffusion in minerals and melts: theoretical background. Rev. Mineral. Geochem. 72, 5-58.

Zhang L., Van Orman J. and Lacks D. (2009) The influence of atomic size and charge of dissolved species on the diffusivity and viscosity of silicate melts. Am. Mineral.94, 1735-1738. 


\section{DISCLAIMER}

This document was prepared as an account of work sponsored by the United States Government. While this document is believed to contain correct information, neither the United States Government nor any agency thereof, nor The Regents of the University of California, nor any of their employees, makes any warranty, express or implied, or assumes any legal responsibility for the accuracy, completeness, or usefulness of any information, apparatus, product, or process disclosed, or represents that its use would not infringe privately owned rights. Reference herein to any specific commercial product, process, or service by its trade name, trademark, manufacturer, or otherwise, does not necessarily constitute or imply its endorsement, recommendation, or favoring by the United States Government or any agency thereof, or The Regents of the University of California. The views and opinions of authors expressed herein do not necessarily state or reflect those of the United States Government or any agency thereof or The Regents of the University of California.

Ernest Orlando Lawrence Berkeley National Laboratory is an equal opportunity employer. 